\title{
Nurses’ Labour Supply Elasticities: the Importance of Accounting for Extensive Margins*
}

\author{
Barbara Hanel $^{\mathrm{a}, \dagger}$, Guyonne Kalb ${ }^{\mathrm{a}}$ and Anthony Scott ${ }^{\mathrm{a}}$
}

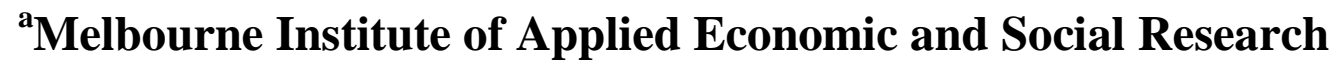

The University of Melbourne

${ }^{\dagger}$ Correspondence should be directed to Barbara Hanel, Melbourne Institute of Applied Economic and Social Research, Faculty of Business and Economics Building, Level 5, 111 Barry St., University of Melbourne 3010, Australia, bhanel@unimelb.edu.au, +61 3 90354565.

*Funding from ARC linkage grant LP0669209 and the Victorian Department of Health is gratefully acknowledged. The paper uses the unconfidentialised unit record file from the Department of Families, Housing, Community Services and Indigenous Affairs' (FaHCSIA) Household, Income and Labour Dynamics in Australia (HILDA) survey managed by the Melbourne Institute of Applied Economic and Social Research. We would like to thank Richard Blundell, Deborah Cobb-Clark and Denise Doiron for their comments and suggestions on an earlier draft. We are also grateful for feedback and suggestions by participants at the $3^{\text {rd }}$ Australasian Workshop on Econometrics \& Health Economics, 2011 HILDA conference, the Microeconometrics Workshop at the University of Melbourne, the School of Economics Seminar at the University of Sydney, and the IAB Colloquium in Nuremberg. The views expressed in this paper and any remaining errors are those of the authors solely. 


\begin{abstract}
We estimate a multi-sector model of nursing qualification holders' labour supply in different occupations. A structural approach allows us to model the labour force participation decision, the occupational and shift-type choice, and the decision about hours worked as a joint outcome following from maximizing a utility function. Disutility from work is allowed to vary by occupation and also by shift type in the utility function. Our results suggest that average wage elasticities might be higher than previous research has found. This is mainly due to the effect of wages on the decision to enter or exit the profession, which was not included in the previous literature, rather than from its effect on increased working hours for those who already work in the profession.
\end{abstract}

\title{
Keywords
}

Nursing; Labour Supply; Shift Work; Wage elasticities

\section{JEL Code}

J22, J24, I10, I11 


\section{Introduction}

Maintaining an adequate supply of nurses is a key ongoing policy issue in many countries. The World Health Organisation (2006) estimated global shortages of health workers of 4.3 million. Shortages are important in the light of evidence, largely from the US, of the impact of the level of nurse staffing on patients' health outcomes (Lankshear et al., 2005; Kane et al., 2007, Cook et al., 2010). It is clear that shortages are common across many low and high income countries, which means that research on the determinants of nursing labour supply remains a priority. Even where overall shortages are less of an issue, shortages in specific sectors, disease areas, and geographic areas highlight the role of maldistribution. Although the budgetary pressures from the global financial crisis may have reduced demand for nurses employed in the public sector in some countries, the 'need' for health care, and therefore for nurses, continues to grow as the population ages and as developing countries continue to struggle to provide basic health services. Shortages are a long-term issue since labour markets, especially for nurses who work in the public sector, are often slow to adjust to changes in demand and supply conditions partly due to centralised wage bargaining. At the same time, the nursing workforce is also ageing and a high number of 'baby boomer' nurses are leaving the profession as they retire. This trend is aggravated by relatively low numbers of young graduates who enter the profession.

The stock of trained nurses who could in principle work in the profession but are currently not doing so is relatively high. For example in Australia, around $17 \%$ of registered or enrolled nurses were not working as nurses in 2005 (Australian Institute of Health and Welfare (AIHW), 2008). Raising wages in order to attract them back to the profession may be one possible option to tackle the problem, but increasing wage offers will be an optimal strategy for the demand side of the market (i.e. public and private health care providers) only if the response of the supply side is strong enough. Otherwise, the cost of inducing any substantial change in labour supply will be too high and have an even greater dampening impact on demand. Most previous research suggests that the labour supply elasticity with respect to wage is fairly low among nurses at around 0.3 (see Antonazzo et al. (2003) and Shields (2004) for a review). However, a major drawback of these studies is that they do not model the decision to exit or enter the nursing profession versus other occupations. The elasticity of labour supply in nursing at the extensive margin might differ considerably from that at the intensive margin. This is of particular importance as the nursing workforce primarily consists of women. Not only is their general labour force attachment lower than 
that of men, but their career paths, moving out of and back into the labour force around childbirth, also lower the opportunity costs of changes in occupation and thus make career changes more likely. In order to obtain reliable estimates of the total labour supply elasticity in nursing, it is thus important to model not only individuals' labour force participation decisions - which has been done in previous research using a broad range of methods - but also their occupational choices.

This paper seeks to investigate the viability of wage policies to increase nurses' labour supply through a multi-sector labour supply model. We extend the literature by considering a sample of nursing qualification holders, rather than those who work as registered nurses only. This means that our sample contains potentially available nurses regardless of their labour force participation and regardless of the occupation they are currently working in. Thus our sample enables us to model the extensive margin not only in terms of workforce participation (Creedy and Duncan, 2002), but also in terms of choice of non-nursing occupations. This allows us to address the following questions: 1 ) how responsive is the decision to enter the nursing profession to wages in nursing?, 2) how responsive is the decision to exit the profession to wages in non-nursing occupations?, and 3) is the estimated total elasticity of labour supply in nursing higher than suggested by previous research, once transitions between nursing and other occupations are allowed for in the model? The answers to these questions will indicate whether increasing wages in nursing could be a more promising policy to tackle the problem of nurse staffing shortages than previously thought.

Additionally, we examine the choice for shift type (distinguishing regular day shifts, regular night shifts and irregular shifts) as part of nurses’ labour supply. In our structural approach employment in different shift types enters the utility function as separate arguments. This leads to our fourth research question: 4) does the responsiveness of labour supply to wage changes differ by shift type? A further novelty of our research is that we investigate the importance of family circumstances for nurses' labour supply, as these are expected to affect the utility derived from income and the disutility derived from working hours in nursing jobs with different shift types or a non-nursing occupation. This leads to our final research question: 5) to what extent does the responsiveness to wage changes depend on a nurse's family circumstances?

To give a preview of our findings, the results suggest that nurses' labour supply might be more responsive to changes in wages than earlier research concluded, as we find an average 
elasticity of hours worked in nursing with respect to nursing wages of 1.3. This higher elasticity is due to changes in the entry into and exit from the nursing profession in response to wage changes. Earlier research has ignored the possibility of entry from or exit to other occupations. Work in night shifts turns out to be associated with a higher disutility from work than work in other shift patterns, and thus the responsiveness to wages is considerably smaller. Estimating labour supply elasticities for different groups of nurses with different family circumstances, it is found that the labour supply elasticity with respect to other nonlabour income is considerably higher for nursing qualification holders with children and for those with a higher qualification. For the labour supply elasticity with respect to nursing wages, it is found that lower qualified, childless, and older nursing qualification holders respond more strongly to a given wage increase than their counterparts.

The paper continues as follows. Section 2 briefly discusses previous literature, and Section 3 the proposed estimation strategy. This is followed in Section 4 by a description of the data, including some summary statistics. The results are presented in Section 5. Section 6 concludes.

\section{Literature Review}

Antonazzo et al. (2003) and Shields (2004) provide extensive reviews of the literature on the labour supply of nurses. The majority of studies find that nurses' labour supply is fairly unresponsive to wages, at an elasticity of around 0.3 (Shields, 2004). A major methodological challenge in modelling labour supply in the highly female-dominated profession of nursing is to model the labour force participation decision together with the decision about the number of hours worked. Previous studies have applied a broad range of methods to deal with the endogeneity of the participation decision. Early studies estimated systems of equations using a 2SLS- or 3SLS-framework based on regional data, where a continuous hours equation is estimated simultaneously with an equation representing the labour force participation rate in the region (Benham, 1971; Link and Settle, 1981b). Some studies based on individual data apply Tobit models for the estimation of working hours (Sloan and Richupan, 1975; Link and Settle, 1979; Link and Settle, 1981a). In later studies, Heckman selection models are used to estimate the number of supplied working hours while accounting for the participation decision (Link, 1992; Ault and Rutmann, 1994; Chiha and Link, 2003). The use of panel data is rare, given the scarcity of panel data on nurses. Among the first studies using panel data are Askildsen et al. (2003) and Rice (2005). While Rice (2005) used data from the British 
Household Panel Study, Askildsen et al. (2003) drew upon a large panel data set of registered nurses in Norway. Askildsen et al. estimated the number of supplied hours together with a participation equation, accounting for unobserved heterogeneity through correlated error terms. Regardless of the applied estimation methods, with few exceptions (e.g. Sloan and Richupan, 1975; Link and Settle, 1985), previous studies found the elasticity of working hours as well as the elasticity of labour force participation to be well below one, i.e. nurses' labour supply appears to be relatively inelastic with respect to wages.

Recent research has therefore paid more attention to other, non-monetary, factors that might drive nurses' labour supply, such as relations with colleagues, degree of autonomy, or intrinsic rewards (e.g. Clark, 2001). Shields and Ward (2001) investigate the role of job satisfaction for nurses' intentions to quit the profession, and find that satisfaction with promotion and training opportunities are of higher importance than, for example, satisfaction with wages. This has also been investigated using discrete choice experiments (Lagarde and Blaauw, 2009; Lagarde, 2010). The range of job characteristics that might be relevant for nurses' labour supply is broad. One job characteristic that seems to distinguish nursing jobs from most other professions is the high incidence of shift work. Only two studies have examined shift work in a labour supply context. Askildsen et al. (2003) use the shift type in a nurses' work contract as an explanatory variable for the number of supplied hours and find it to be an important determinant that influences the size of the wage elasticity. Di Tommaso et al. (2009) are the first to model shift type as a choice together with supplied hours in a discrete choice setting. In their structural model the labour supply decision is the solution to an individual's utility maximization which has leisure (or its complement, hours of work) and consumption (usually assumed to be equivalent to net income) as its arguments. Hours worked in different types of jobs (day shifts versus rotating shifts, and hospitals versus primary care facilities) enter the utility function as separate arguments. While they find the overall elasticity of labour supply to be rather low, they find strong inter-job-type responses to wages. Moreover, work in irregular shifts responds more strongly to a wage increase than work in regular day shifts.

We build on the approach used by di Tommaso et al. (2009). A structural multi-sector model of labour supply is ideally suited to answer the research questions raised in the introduction: how is the decision to supply labour in nursing versus another occupation affected by wages in nursing and wages in competing professions? Is the labour supply elasticity different for work in different shift patterns? Similar to di Tommaso et al. we estimate a discrete choice 
labour supply model with work in different jobs entering the utility function as separate arguments. We extend their approach, however, by using a sample of nursing qualification holders, rather than those who work as registered nurses only. ${ }^{1}$ Hours of work in different shift patterns and in different occupations enter the utility function as separate arguments. Maximisation of this utility function then determines the labour force participation decision, the hours decision and the occupational choice. However, while many of the studies discussed above model the labour force participation decision, the individual's occupational choice has not been incorporated in the estimations. Given the number of nurses leaving the occupation, understanding how these nurses can be attracted back to the profession and how current nursing staff can be prevented from leaving will inform policy makers in the design of effective policies, keeping nurses' labour supply at a higher level. What is needed to keep nurses from leaving specific shift types may well differ. A better understanding of this latter aspect is also crucial for effective policy making.

\section{Estimation Strategy}

We estimate a structural model of individual labour supply, directly based on an underlying utility function, to obtain estimates of labour supply elasticities with respect to income and wages. The utility function has household net income (assumed to represent household consumption) and four different types of working hours as its arguments: working hours in non-nursing jobs, and working hours in nursing jobs in the three different shift types 'regular day shifts', 'regular night shifts' and 'irregular shifts'. It is assumed that nursing qualification holders choose hours so that utility is maximised. We use a quadratic specification for the utility function (following Keane and Moffitt, 1998). The quadratic specification is simple but quite flexible in that it allows for the leisure of each person and consumption to be substitutes or complements. This means the model can represent complex interactions. Furthermore, the quadratic utility function can be expressed as a function of labour supply rather than leisure without the need to choose a value for total endowment of time as would be required in alternative specifications. These advantages make the quadratic utility function a good choice, even though it is not automatically quasi-concave. However, in a discrete labour supply model this is not a problem, because if utility $U$ is increasing in income at the observed income and leisure time, and the matrix of second order derivatives of income with respect to leisure along the indifference surface is positive at the observed income and leisure time, then $U$ is quasi-

\footnotetext{
${ }^{1}$ This allows us to analyse the decision to work in nursing versus working in another occupation or being out of the labour force, and to examine the response to wages in competing professions together with the response to wages in nursing.
} 
concave at that point (Varian, 1992: pp. 96-97). In the discrete approach taken here, these two conditions can be tested at all data points after estimation of the parameters. ${ }^{2}$

In each period, each nursing qualification holder $i$ can choose between alternatives $j$ from a set of combinations $M$ of income and working hours in different employment types: $\left\{\left(y_{j i}, h d_{j i}\right.\right.$, $\left.\left.h n_{j i}, h i_{j i}, h o_{j i}\right) ; j=1,2, \ldots, m\right\}$ where $h d_{j i}, h n_{j i}$ and $h i_{j i}$ denote the individuals' working hours in nursing jobs, either in regular day shifts $(h d)$, regular night shifts $(h n)$ or in irregular shifts (hi), and ho are working hours in non-nursing jobs. $y$ is the household net income associated with the choice of working hours and employment type. The quadratic utility function to be estimated is:

$$
U_{j i}=\beta_{0} y_{j i}+\beta_{1} y_{j i}^{2}+\sum_{x=d, n, i, o}\left(\beta_{2 x} h x_{j i}+\beta_{3 x} h x_{j i}^{2}+\beta_{4 x} h x_{j i} y_{j i}\right)
$$

We estimate various specifications where we allow the linear preference parameters $\beta$ in the utility function to differ by family status.

Labour supply is treated as a discrete choice problem rather than a continuous choice, similar to the approach by Van Soest (1995). This approach is chosen for a number of reasons. First, since we want to distinguish the choice between four types of occupation (three nursing occupations with different shift types and other occupations combined), which is a discrete choice. Second, in the labour supply literature it has been shown that a discrete representation of continuous labour supply is adequate, and perhaps even preferred since in reality workers often have a limited number of hours of work they can choose from. We estimate the model for a number of different labour supply points to explore the sensitivity to a different number of points, and to find the minimum number of points at which the results become stable (i.e. the point at which they do not change much when increasing the number of points). Third, we can estimate the preference parameters in the utility function directly, allowing the model to be used to predict the effects of any policy changes that affect net income. Fourth, in a model with continuous hours of labour supply, quasi-concavity conditions would need to be imposed a priori to guarantee coherency, substantially complicating estimation.

In 2002, Creedy and Duncan already noted "...in recent years there has been a move towards discrete modes of estimation." (p. 13), and this move has continued up to now. The discrete

\footnotetext{
${ }^{2}$ Allowing for expressing utility as a function of hours worked instead of leisure, we have checked for these two conditions. In our case, they were found to be fulfilled in $99.24 \%$ of the observations.
} 
choice labour supply model is particularly popular in the context of tax and transfer behavioural microsimulation modelling.

We observe between 0 and 80 working hours per week, measured in one-hour units. Individuals can hold more than one job, and thus different combinations of working hours in different hours-types are possible. To maintain computational tractability, we apply two simplifying assumptions: i) for each alternative, only one of the variables $h d, h n, h i, h o$ is allowed to be positive, ${ }^{3}$ and ii) we allow three discrete labour supply choices (which means that we approximate actual labour supply by one of the choices). ${ }^{4}$ The discrete labour supply points are chosen in such a way that the actual labour supply is represented as well as possible. ${ }^{5}$ This leaves us with twelve different choices of employment, and we add a thirteenth alternative "non-employment”, where hours in each of the four different work arrangements and labour income is set to zero.

The utility function is approximated by a deterministic component represented by the quadratic function specified in (1), plus a random disturbance that is assumed to follow a type I Extreme Value distribution. Choosing an extreme value specification for the error term results in a multinomial logit model (see Maddala, 1983). Due to the tractability of the multinomial logit model, this choice has been popular in discrete choice labour supply modelling.

The basic assumption underlying the model estimation is that every individual chooses the alternative that leads to the highest utility. There is reasonable support for this assumption of utility optimisation since actual hours worked and preferred hours of work correspond quite closely. Preferred hours are measured in HILDA by asking employed respondents "whether and how many hours per week they would prefer to work more or less than they currently do, taking into account how that would change their income". For $72 \%$ of all observations on employed individuals, the reported preferred working hours fall in the observed hours interval. For those working in nursing this is even higher at $74 \%$. This is some indication that

\footnotetext{
${ }^{3} 89.7 \%$ of the observations in the sample do not hold more than one job and are thus not affected by this restriction. For those who hold more than one job, the shift pattern in the main job is considered to determine the chosen alternative. The shift pattern in other jobs is not observed. Hours worked in all jobs are added together.

${ }^{4}$ The intervals of working hours per week are $[4,25],[26,37]$ and $[38,80]$. The discrete hours points $h d_{j}, h n_{j}$, $h i_{j}$ or $h o_{j}$ are set to the average number of hours worked observed in each of these intervals, and the average number of hours worked is used to determine the corresponding labour income at that labour supply point. Individuals working less than 4 hours per week are considered to be non-employed.

${ }^{5}$ We also examine the sensitivity of results to choosing a larger number of labour supply points: four, six and eight instead of three. This does not change the estimated elasticities much. Selected results are included in Appendix C, and the full results are available from the authors upon request.
} 
nursing qualification holders may be slightly better able to optimise their hours than individuals in other professions, and certainly no worse. This is possibly due to the shortage of nurses' supply. Thus we can expect models of labour supply, which are based on the assumption that people can choose their hours freely, to work at least as well for nursing qualification holders as for other groups. In addition, the distribution of hours worked within each shift type suggests that both part-time and full-time hours ranges are well covered (see Table 1). This indicates that a broad range of combinations of shift type and hours worked is on offer, providing nursing qualification holders with varied choices of shift type and hours worked, facilitating the supply of preferred hours without facing demand side constraints. ${ }^{6}$

Restricting the number of possible working hours to a limited set of discrete values has the advantage that for this limited set of hours, one can calculate the level of utility that each possible combination of hours and occupation would generate, according to the specified utility function. If we can calculate utility levels for each of the discrete values of hours of work and income, and the error terms are specified, then for each possible combination we can calculate the probability of that combination being preferred according to the estimated model. Under the assumption of a type I Extreme Value error term, the probability that individual $i$ chooses alternative $j$ (from the $m$ alternatives) is:

$$
\operatorname{Pr}\left(U_{j i}>U_{k i}, k \neq j\right)=\exp \left(U_{j i}\right) / \sum_{k=1}^{m} \exp \left(U_{k i}\right)
$$

To estimate these probabilities, we need to know the budget constraint in order to determine the household net income (and thus the utility level) associated with each choice $j$. Hourly gross wages for the different shift types in nursing and for working in non-nursing jobs are predicted for all nursing qualification holders using wage regressions. We regress wages in non-nursing occupations on tenure (as a proxy for job-specific human capital), age (as a proxy for labour market experience and thus general human capital), and state and year dummies. Age and tenure enter the model in linear, quadratic and cubic terms. Age and tenure are fully interacted with a dummy variable indicating tertiary education. A separate

\footnotetext{
${ }^{6}$ Individuals who are most likely to be facing demand side factors that lead to sub-optimal working hours are those for whom observed hours are not equal to preferred hours. This may potentially lead to bias in the estimation of the model's parameters due to measurement error. Therefore, in the empirical section of the paper, we follow Ribeiro (2001) who uses information from the sample (whether workers were looking for another job) to exclude individuals from the analysis, and estimate an alternative version of the model, excluding all observations who are not working at their preferred hours. This provides an indication of the bias of the estimated elasticities due to sub-optimal labour supply reported in the data.
} 
regression equation for nurses' wages has the same functional form, but additionally includes a dummy variable that indicates the shift type, which is again interacted with tertiary education. Using tenure in the wage models allows us to capture nurses who have been in nursing for a longer time and so are less likely to switch occupation. Tenure in the nursing wage models will be high, and tenure in another occupation would be zero, thus making the relative wage in nursing higher than for nurses with lower levels of tenure. Naturally the reverse is true as well, with longer tenure in other occupations making the wage in other occupations more attractive relative to nursing.

To account for selection into employment and into nursing, we apply a two-step Heckman selection model. The participation decisions for employment in nursing and for employment in other occupations are estimated as a function of age, education, gender, State and year, family circumstances (presence of a partner and partner's employment status, as well as the presence of children and interactions between children and partner's characteristics). ${ }^{7}$

Using the estimated wage models, the expected gross labour income at different choices of hours worked per week can be calculated. Non-work household income and partner's gross income are treated as exogenous. The sum of resulting labour income, other non-labour income and partner's income is used to compute taxes paid and family payments received by both partners based on the relevant tax and transfer system (which were slightly different for each of the years observed in the data). ${ }^{8}$ The resulting net household income is adjusted for inflation using the consumer price index depending on the year of observation.

The most important advantages of this type of model for our analysis are i) that we fully incorporate the participation decision and the hours decision in the same modelling framework and thus our results are not biased by endogenous sample selection into working as a nurse, ii) that the choice for different shift types and occupations can be incorporated in the model easily, and iii) that the direct estimation of the utility function allows us to simulate responses to different wage policies. A minor limitation of the approach used in this paper is that the partner's labour supply is treated as exogenous. Although the model in principle

\footnotetext{
${ }^{7}$ As a robustness check, we have repeated the estimation with predicted wages from a simple OLS regression without controlling for selection into employment. The results are very similar, and results from both wage models are available from the authors upon request.

${ }^{8}$ Included in the calculation of payable taxes and government payments are income tax, low income rebates, dependent spouse rebates, Medicare levy and Medicare levy surcharge, as well as family tax benefit part A and family tax benefit part B. See http://www.centrelink.gov.au/internet/internet.nsf/publications/co029.htm for an overview of the current (and recent) Australian social security system and http://www.ato.gov.au for the Australian tax system..
} 
allows estimating partner's labour supply jointly by extending the set of choices for couple families, this is not a feasible strategy given the size of the data set (see Section 3), since it would require separate models for single-adult and two-adult families. ${ }^{9}$

\section{Data}

\subsection{Description and Summary Statistics}

In this analysis, we use pooled data from nine waves (2001-2009) of the Household, Income and Labour Dynamics in Australia Survey (HILDA). HILDA is an annual household survey that is representative of all Australian households; individual interviews are conducted with all members of selected households who are aged 15 or over. In their first interview, respondents are asked whether they hold a nursing qualification. In subsequent waves, respondents are asked whether they gained any further qualifications since the last interview. It is not known, however, whether any of these further qualifications were obtained in nursing. We assume that a qualification gained after the first interview is a nursing qualification, if the individual works in nursing within two years of gaining the additional qualification. Whether an individual works in a nursing occupation is determined based on the 4-digit ANZSCO-Code. Nursing occupations include Midwifery and Nursing Professionals, Enrolled Nurses, Nursing Support Workers and Personal Care Workers. 4,933 observations of 788 individuals with a nursing qualification are available in HILDA across waves 1 to 9.

We exclude all observations after they reach age 65, observations of individuals with missing information on hours worked, on their shift type or on their partners, and individuals with a reported weekly net household income higher than $\$ 10,000$ or lower than $\$ 200$. The remaining sample contains information on 696 nursing qualification holders (3,972 personyear observations), of whom 474 are observed working in a nursing occupation at least once during the observation period (2,041 person-year observations). The data also show that a substantial proportion of nursing qualification holders work outside nursing (27.1\% of all

\footnotetext{
${ }^{9}$ The approach of treating partner's labour supply as exogenous is frequently used in the literature on nurses' labour supply, as is evident from the review of labour supply studies on nurses by Antonazzo et al. (2003). This approach is also adopted by a recent study by di Tomasso et al. (2009) on which this paper builds. The approach of treating partner's labour supply as exogenous has also been used in recent studies on mother's labour supply and childcare decisions (Kornstad and Thoresen, 2007; Breunig et al., 2012). In these cases including the partner's labour supply would make the model more computationally demanding and lead to few additional insights, since their labour supply behaviour was unlikely to be very responsive to, for example, childcare cost. In addition, given that the majority of partners (82\%) in our data are working and are working full time (81\% of working partners work 38 hours or more), treating the partner's labour supply as exogenous is a reasonable simplification.
} 
person-year observations), indicating that nursing qualification holders can quite easily move to other occupations. Six hundred and three nursing qualification holders are observed at least twice. In this group, 111 change from a nursing occupation to another occupation at least once (18.4\%), and 103 from a non-nursing occupation to a nursing occupation (17.1\%) with 67 individuals observed in both groups. Within the 9-year observation period we observe a total of 184 transitions from another occupation or out of the labour force into nursing, and 216 exits from nursing into other occupations or out of the labour force.

HILDA provides information on hours worked in nursing occupations in different shift types and hours worked in other occupations. Potentially important personal characteristics include, besides socio-demographics controls such as age, gender and highest educational degree; the family circumstances (presence of a partner and of young children, partner's employment status, partner's income and partner's education); and information on the level of the respondent's satisfaction with their partner and a variable that indicates if they feel a lack of support. We also explored the relevance of the nursing qualification holders’ personality which is measured in five dimensions: extroversion, emotional stability, openness to new experiences, agreeableness and conscientiousness (the "Big Five”). However, these personality traits are not found to be very important, so we have only included them in the descriptive statistics and models, and we have left out these results from the labour supply model. $^{10}$

Table 2a shows descriptive statistics for the nursing qualification holders. The vast majority is female, less than $10 \%$ are male. The individuals in our sample are 45 years old on average, one out of five has a tertiary educational degree in nursing, and they work 25 hours per week on average. Those who have a job in nursing are about three years younger, work six hours per week more, and are more likely to hold a bachelor degree. Of those with a job in nursing, $74 \%$ work as a registered nurse or midwife, and $12 \%$ as an enrolled nurse or mothercraft nurse. The partner characteristics of those who work in nursing and the average nursing qualification holder appear to be similar: about two thirds live with a partner, the vast majority of partners is employed (although more so for those still working in nursing), about $40 \%$ of partners hold bachelor degrees, and partners' income is comparable for both groups. However, those who work in nursing are more likely to have young children below age 5 . This is in line with Dockery and Barns (2005), who find that flexible working arrangements

\footnotetext{
${ }^{10}$ Readers who are interested in these results can request them from the authors.
} 
in nursing jobs are an important motivation to study nursing for young women who intend to have children.

Table $2 \mathrm{~b}$ reports average predicted hourly wages in non-nursing occupations and in nursing by shift type. ${ }^{11}$ Predicted wages for nursing qualification holders who are currently not working are substantially lower than for those in employment, regardless of the occupation or shift type they would commence work in. This is in line with self-sorting into employment. Nurses working in regular night shifts have a lower predicted wage level as well, reflecting their somewhat lower educational attainment. Nursing qualification holders who work in an occupation other than nursing would have to accept a drop in wages if they were to change to nursing. In contrast to that, nursing qualification holders who do work in nursing can expect higher wage rates if they were to change occupation. Due to the return to experience in an occupation, nursing qualification holders who are working in nursing are predicted to have higher wages in nursing than those who are working in another occupation. Vice versa, nursing qualification holders who are working in a non-nursing occupation are predicted to have higher wages in a non-nursing occupation than those who are working in nursing. Wages across shift types are relatively similar, with irregular shifts and regular night shifts paying somewhat more than regular day shifts for all nursing qualification holders, consistent with collective wage agreements.

\subsection{Correlation Patterns between Employment Type, Shift Type and Family Situation}

In a purely descriptive analysis to show the importance of family situation for the choice of employment type and shift type, we estimate two separate multinomial Logit models on the pooled HILDA data for: i) the type of employment and ii) the shift type conditional on being employed as a nurse. This allows us to examine correlation patterns between nursing qualification holders' characteristics (including interaction terms between the partner's characteristics and the presence of a young child) and their observed work arrangements. Table A1 (in Appendix A) reports marginal effects of individual characteristics on the probability of full-time employment in nursing, part-time-employment in nursing, employment in other occupations, or no employment. ${ }^{12}$

\footnotetext{
${ }^{11}$ The wage rates were adjusted for inflation using the Consumer Price Index calculated for all groups of goods and services in September 2009, as a weighted average of the eight capital cities in Australia (Australian Bureau of Statistics, 2012)

${ }^{12}$ Observations on the same individual are clustered to allow for the panel nature of the data in a limited way by correcting the bias in standard errors arising from correlation between observations on the same person.
} 
While the comparison of individual characteristics in Table 2a did not yield any strong differences in the family situation between those who work in nursing and those who do not, the results are different when we distinguish between not working at all and working in other occupations, and between working as a nurse in full-time jobs or in part-time jobs. The complex patterns implied by the model presented in Table A1 are illustrated in Figure 1. It shows predicted probabilities of different employment types, evaluated at different individual characteristics: with and without young children, without partners, and with employed partners at different levels of the partner's income.

For nursing qualification holders without children, we see almost no variation in the probability of being in a nursing job or not when the partner's income increases and only a slightly decreasing probability of being full-time employed as a nurse instead of being parttime employed. For nursing qualification holders with children, results are very different. Without a partner, working as a nurse is unlikely for those with children compared to those without children. If there is a partner, but with a low income, working in nursing jobs becomes more likely. With increasing partner's income, nursing appears to become less attractive, and there is a large shift from full-time nursing towards part-time nursing. Figure 1 suggests that a) income effects are important in pushing nursing qualification holders out of the profession, and particularly out of full-time nursing, b) that these income effects are more important when children are present, and c) that working as a nurse and raising a child might be easier to organize when there is a partner (and in fact that, in that case, nursing might be a slightly preferred option compared to other occupations).

The latter finding immediately leads to the question whether nurses in different family circumstances work different shift patterns. Table A2 shows the marginal effects of a multinomial Logit model that we estimated for the sub-sample of nursing qualification holders who work as a nurse. The model includes three different outcomes: regular day shifts, regular night shifts and irregular shifts.

Figure 2 shows predicted probabilities for different shift types depending on the family situation. The effect of having children depends strongly on the presence of a non-employed or employed partner with high or low income. The graph suggests that it is the presence of a partner that allows for coordination of working times among parents and thus for irregular shift schedules, which are in turn chosen more often. On the other hand, income effects might decrease the relative attractiveness of the comparatively high-paid irregular shifts, and thus 
increase the probability to work according to a standard schedule when the partner's income is high enough. Both effects seem to be important for nurses with young children, but play a minor role for their childless counterparts.

\section{Results of a Structural Model of Labour Supply - Estimating Labour Supply Elasticities}

We estimate a structural model of nurses' labour supply as outlined in Section 2 to obtain estimates of the elasticity of nurses' labour supply in different shift types with respect to their wages and incomes. ${ }^{13}$ All observations are clustered at the individual level. ${ }^{14}$ Table 3 shows the estimated preference parameters of the quadratic utility function as presented in equation (1), as well as the marginal effects of income and hours worked in the different shift types or a non-nursing occupation on the utility averaged over all individuals. Standard errors of marginal effects are bootstrapped. As expected from theory, utility increases significantly in household net income, and decreases in hours worked. The strongest disutility from work occurs for regular night shifts, although the 95\%-confidence intervals for disutility from work overlap for all types of working hours, except for regular night shifts and irregular shifts (which has the lowest disutility).

The results from section 4.2 indicate heterogeneity in nurses' labour market behaviour depending on characteristics. Differences in labour supply for different population groups may arise from differences in the utility an individual gains from income and leisure. To incorporate such differences in individuals’ utility functions, we estimated additional specifications, that include income and hours worked as in the base model, but also includes interactions of the linear terms of income and hours with personal characteristics. Because of the sample size, it was not possible to include the full range of socioeconomic characteristics and their interactions as described in Section 4.2. Instead, we estimated a more parsimonious specification to explore heterogeneity in the utility functions of nursing qualification holders. This alternative includes interactions of the linear terms of income and hours with age, presence of young children below age 5, presence of a partner and educational degree. Table 4 shows the coefficients of the additional interaction terms. Almost none of them are

\footnotetext{
${ }^{13}$ For the calculation of net income, we estimated hourly wages in different shift types (cf. Section 2). We excluded observations with an hourly wage rate below $\$ 10$ or above $\$ 85$ from the auxiliary wage regression sample. Furthermore, observations were not used for the wage regressions when a wage growth of more than $100 \%$ was observed from one year to the next, followed by an immediate decrease to less than $50 \%$. (cf. Munasinghe et al., 2008) The wage regression results are available from the authors upon request.

${ }^{14}$ To test the robustness of the results, we have repeated the estimation using only the first observation year per individual. There were no substantial changes in the magnitude nor in the significance level of estimated coefficients or elasticities. The results are available from the authors upon request.
} 
individually significant at the five-percent level. However, when tested jointly, the presence of children, age and education are highly significant. This implies that the optimal choice of labour supply, as well as the response of labour supply to changes in wages and income, varies with personal characteristics.

To assess the performance of the estimation, we compared the actually observed labour supply decisions to the choices that are predicted by each of the model specifications in Table 5. The average predicted probabilities for non-employment, occupation and shift types almost equal the observed frequencies, indicating that the model reflects observed labour market behaviour well. Also the number of working hours in each of the shift types and in both occupation types is predicted well by the model, with the exception of working hours in night shifts. The estimated probability of working a high or a low number of hours in night shifts is somewhat higher than the observed frequencies, while the probability of working between 26 and 38 hours is somewhat lower. However, working in night shifts is an infrequent choice, with less than 3\% of the observations being observed as working in each of the hours bands in night shifts, and the absolute difference between observed frequencies and average predicted frequencies is small. Further checks on the performance of the model are presented in Appendix B. First the predicted and observed choices for individuals are compared. Second, making use of the panel aspect of the data, the consistency of the estimated model with the observed transitions from one labour supply choice to another over the nine available years of data is investigated. The results from both checks are re-assuring.

\subsection{Income Elasticity}

After estimating the utility function, we run several simulations to explore the expected labour supply response of nursing qualification holders to different scenarios with respect to income. First, while holding their net labour income constant, we increase the net non-labour income and net partner's income by $1 \%$ to predict the resulting changes in their labour market behaviour. The results, based on Specification (1), can be seen in Column 1 of Table 6a. If we examine the changes in the probability to work in specific shift types or outside nursing jobs, we see that nursing qualification holders are more likely to stop working or to switch into regular day shifts when their non-work income increases.

The second panel of the table gives the expected working hours in day shifts, night shifts, irregular shifts or non-nursing jobs, conditional on being in one of these working arrangements. As one would expect, working hours decrease as a result of the increase in 
other net income. However, the effects are very small in magnitude, and the resulting elasticities are, although significant, close to zero. We get a similar result for expected hours in nursing jobs conditional on working in a nursing job - the resulting elasticity is only -0.04 . However, when we look at the unconditional elasticity of working hours in nursing, this is more than twice as high as the conditional elasticity (although still relatively small). This result implies that most of the changes in expected working hours in nursing are not because working nurses supply less hours when other net income increases, but mainly because nursing qualification holders stop working in nursing. Finally, the overall income elasticity of expected working hours (i.e. in nursing jobs and in non-nursing jobs) amounts to -0.12 , which is comparable to labour supply elasticities with respect to income that were found in the literature for nurses and for females in general before (see for example Skatun et al., 2005; Phillips, 1995 for nurses; Killingsworth, 1983: 193-199 or Blundell and MaCurdy, 1999: 1649-1651 for the general female population; and Birch, 2005 for women in Australia).

\subsection{Labour Supply Elasticity With Respect to Wages}

The second column of Table 6a shows the adjustment of labour market behaviour to an increase in all hourly gross wages (regardless of the occupation and shift type) by $1 \% .{ }^{15}$ As one would expect, the probability of being non-employed decreases, while the probability of employment increases in all working arrangements. Moreover, hours supplied given a certain work arrangement increase, with elasticities ranging between 0.21 (irregular shifts in nursing) and 0.28 (regular night shifts in nursing). Labour supply conditional on working in nursing increases by only 0.07 hours per week which translates into a wage elasticity of about 0.24 , which is at the lower end of the range of previously found wage elasticities for nurses (Shields, 2004), for women in general in Australia and New Zealand (Birch, 2005; Kalb, 2010), for women in general (Blundell and MaCurdy, 1999) and in an overview by Hotz and Scholz (2003) focussing on lower and middle income earners. However, the unconditional elasticity of working hours in nursing with regard to the gross wage is about 0.44 . This is because, in addition to longer working hours, former non-employed nursing qualification holders now also enter the occupation.

The same phenomenon is observed for a third scenario, which is the most interesting one from a policy perspective. Column 3 shows estimated labour supply changes if only the wage rates in nursing occupations increase, while other wage rates are held constant. Not only are

\footnotetext{
${ }^{15}$ For full-time employed individuals, an increase in gross wages by $1 \%$ translates into an average increase in nominal weekly household net income by \$14.42 in 2009.
} 
former non-employed nursing qualification holders now predicted to enter the occupation, but also nursing qualification holders who worked in different occupations. While the conditional elasticity that ignores this possibility by construction remains at 0.24 , the unconditional elasticity now increases from 0.44 to 1.37 . This elasticity is not readily comparable to those in other studies since it allows for entry of nursing qualification holders currently working in other occupations into nursing. Therefore, even if overall hours worked do not change much, a shift from other occupations into nursing may take place, resulting in a high elasticity.

We have checked the sensitivity of this key elasticity to excluding nursing qualification holders who are not working at their preferred hours from the analysis. Although the estimated elasticity for this restricted sample is somewhat smaller at 1.21, it is still substantially larger than previous estimates leaving the main conclusion from this analysis unchanged. $^{16}$

Naturally, the reverse pattern is found when only wages in competing jobs are raised, which leads to a decline in labour supply in nursing. The labour supply elasticity in nursing with respect to non-nursing wages is estimated around -0.93 .

While the labour supply elasticity with respect to wage in the profession is relatively high, there are two reasons to look at this result with some caution. First, the relatively small sample size only allowed us to define a limited number of labour supply points per employment type, which is an approximation of the full set of choices a nursing qualification holder faces. However, comparing our basic model estimated using three labour supply points with one based on four, six, and eight labour supply points, we find that the results are very similar, indicating that the results are not sensitive to increasing the number of points (see Appendix C). Second, there is measurement error in wages, as the exact feasible wage if a nursing qualification holder was to exit or enter the profession is unknown. Both issues lead to imprecise estimates. However, while the magnitude of the point estimate may not be precise, there is an important conclusion that can be drawn. It appears that the number of supplied working hours is fairly unresponsive to wages, yet the decision to enter the occupation, be it from non-employment or from other occupations, is far more responsive. Therefore, if policy makers aim to increase nursing labour supply, nursing qualification holders who currently do not work in nursing appear to be an important target group.

\footnotetext{
${ }^{16}$ Ikenwilo and Scott (2007) have also found that excluding individuals at suboptimal hours of work does not change their results much. They therefore used the results from their full sample to avoid potential sample selection problems; an approach that we follow as well.
} 
Figure 3 shows the distribution of labour supply elasticities for the different wage and income changes described before, rather than just the average elasticities as shown in Table 6a. The figure clearly shows the heterogeneity in estimated elasticities across the sample. That is, not all nursing qualification holders respond to wage and income changes to the same extent. We observe that each individual in the data set has a negative labour supply elasticity with respect to net non-labour income, and a positive elasticity with respect to wages, be it nursing wages, non-nursing wages or both. The picture gets somewhat more complicated if we look at the elasticity of labour supply in nursing jobs only: while the vast majority of nursing qualification holders in the dataset decrease their expected hours in nursing when other net income increases, a small proportion will increase their labour supply in nursing. These are individuals who currently work in non-nursing jobs and decide to change the occupation due to an increase in other net income, in most cases into regular day shifts. Likewise, an increase in wages regardless of the occupation, i.e. an overall wage growth in real terms, leads to an increase in labour supply in nursing for most qualification holders as expected, although a small group will exit nursing and enter other occupations in response to such an economic development. If wages are increased in nursing occupations only, an incentive is provided to increase working hours in nursing jobs unambiguously. Of course, the reverse pattern is found if wages grow in competing jobs.

\subsection{Labour Supply Elasticity with Respect to Wages in Certain Shift Types}

To examine whether and to what extent a shortage in nurses' labour supply in a particular shift type could be addressed by a wage increase in that particular shift type, we carried out three additional simulations: hourly gross wages in a given shift type were increased by $1 \%$, holding wages constant for all other work patterns, non-nursing jobs and other household income constant. The results are presented in the three columns of Table 6b. In each case, as one would expect, the probability of working in the now higher-paid shift type increases, while the probabilities of working in any other work arrangement and of non-employment decrease. Only about half of the increase in the probability of working in the shift type for which the wage was increased is caused by previously non-employed nursing qualification holders and those who worked in other occupations. The other half of the effect stems from changes in the labour supply decision within the current nursing workforce. This result is in line with di Tommaso et al. (2009), who find that increasing wages lead to substantial shifts of labour supply between job types. Conditional on shift type, expected working hours increase by about 0.07 to 0.08 hours per week, which translates into a labour supply elasticity 
of about 0.21 to 0.28 . The unconditional labour supply elasticity is much higher around 2, but standard errors are large. The $90 \%$ confidence intervals around the point estimates range between 1.5 and 3.2 across the three shift types. Again, this demonstrates that labour supply in nursing is more responsive at the extensive margin than it is at the intensive margin. The overall responsiveness of labour supply in nursing to a wage change in a specific shift type varies by the proportion of nurses working in each shift type. That is, the smallest effect is observed for a change of the wage in night shifts, which is the smallest shift type (see Table 2a).

\subsection{Heterogeneity in Nurses’ Labour Supply Elasticities}

As described in the introduction of Section 4.2, the utility function estimated in Specification (2) varies with personal characteristics, which allows labour supply elasticities to vary by characteristics. The elasticities of labour supply with respect to income and with respect to nurses' wages respectively are shown in Table 7 and Table 8 for six subgroups. Although the standard errors are, again, large and thus none of the elasticities are significantly different from each other across groups, some interesting patterns are found. First, considerable difference in responses to increased non-labour income can be seen for nurses with and without children. While nursing qualification holders without children will increase the probability of supplying labour in day shifts along with the probability of quitting work, nursing qualification holders with children are expected to increase their probability of nonemployment by a larger amount. Consequently, the elasticity of working hours in nursing and overall working hours is nearly twice as high for individuals with children compared to their childless counterparts. The reverse is true for the response to increased wages. Childless nursing qualification holders increase their expected working hours in nursing by nearly twice as much as nursing qualification holders with children, and the corresponding labour supply elasticity is 1.70 for those without children, and only 0.89 for those with children. As the total response to a wage increase consists of the sum of the negative income effect and the positive substitution effect, the stronger, negative income elasticity of nursing qualification holders with children contributes to their lower wage responsiveness.

The second columns of Table 7 and Table 8 show the income elasticity and wage elasticity by educational level. Highly qualified nurses respond less to wage incentives than lowerqualified nurses, although their responsiveness to other income is comparable. This might be due to higher intrinsic rewards from work for nurses who work in higher positions, but also 
be due to the higher cost of changing occupation or leaving the labour force for those who have invested more in their nursing-related education. When we examine differences in the wage elasticity, a similar pattern is found for older vs. younger nurses: for older nurses, the probability of being non-employed or being employed in another occupation is much more responsive to a given wage increase than for younger nurses, which is (considering that their responsiveness to other income is comparable) in line with a weaker labour market attachment of the older population.

\section{Conclusions}

Can wage policy help to maintain an adequate level of nurse staffing? How responsive are nurses to relative wages in nursing versus other occupations in their decision to exit and enter the profession? Our evidence shows nurses' labour supply elasticity to be higher than previous research suggested. Wage increases thus appear to be a more promising policy to increase labour supply than was implied by previous research. We have estimated a structural model of labour supply for nursing qualification holders that distinguishes explicitly between working in different shift types and in different occupations. The responsiveness of nursing qualification holders with respect to wages in nursing jobs is high at an elasticity of 1.37 , and this result is mainly due to our explicit inclusion of the decision to enter and exit the occupation, rather than examining only changes in the number of hours worked of those already working in nursing. Our results thus show that nursing qualification holders who currently do not work in nursing are an important group to target from a policy perspective. At the same time, wage increases for non-nursing jobs are expected to draw individuals out of nursing occupations to almost the same extent as increases in nursing wages might attract nursing qualification holders, who currently work in another occupation, back to nursing. The high responsiveness of the occupational choice implies not only that wage increases in nursing are a promising policy for governments to increase labour supply in the public sector, but also that it is crucial to ensure that wages in nursing do not fall behind the development of wage levels offered in the alternative occupations for nursing qualification holders, as this will reduce labour supply in nursing substantially.

Naturally, nurses' observed hours of work are not solely determined by the supply side of the nurses market. The demand side influences nurses' observed hours of work as well, e.g. through restricting the number of combinations of shift type and hours worked on offer. We have investigated the sensitivity of results to this by exploring how results would change if 
only nurses at their optimal (or preferred) labour supply are included in the analysis. It turns out that this would reduce the elasticity from 1.37 to 1.21 , which remains a substantial elasticity, still indicating a potential role for wage policy. The majority of nursing qualification holders are at their preferred hours of work (72\%), and perhaps those who are not quite at their preferred hours are not far away from them, so that the impact of including those at sub-optimal hours in the analysis is not large. From the observed hours of work and shift type combinations (Table 1), it appears that a broad range of choices are available to employees in this sector, making it more likely that they work at their preferred hours.

A further finding is that changes in wages for certain shift types are predicted to result in considerable shifts in labour supply between shift patterns, which is in line with previous research. If policymakers increase wages for a specific shift type only, they need to be aware that such a policy will lead to a decrease in labour supply in other shift types to a substantial extent, as about half of the labour supply response is caused by the current nursing workforce changing shift type, rather than by attracting nursing qualification holders who are currently not working in nursing, or by increasing of supplied hours of nurses who work in the shift type already. Increased labour in one shift type thus comes at the cost of decreased labour supply in another, if wages are increased only for certain shift patterns. Such a policy may therefore be useful to adjust the distribution across shift types when there is a mal-distribution across shift types, but it is unlikely to provide a solution when there is a shortage in one shift type without oversupply in other shift types.

Comparing wage and income elasticities for different groups of nurses, shows that wage elasticities are higher for low qualified, older and childless nursing qualification holders. At the same time, available non-labour income plays a particularly important role for nursing qualification holders with young children. This indicates that wage policies are not going to be equally effective amongst all individuals who hold a nursing qualification. Some groups will be far more responsive than other groups. This needs to be considered in designing wage policies. 


\section{References}

Antonazzo E, Scott A, Skatun D, Elliot R. The labour market for nursing: a review of the labour supply literature. Health Economics 2003; 12; 465-478.

Askildsen J, Baltagi B, Holmas T. Wage Policy in the health care sector: a panel data analysis of nurses’ labour supply. Health Economics 2003; 12; 705-719.

Ault D, Rutman G. On selecting a measure of labour activity: evidence from registered nurses, 1981 and 1989. Applied Economics 1994 26, 851-863.

Australian Bureau of Statistics. Consumer Price Index 2012; Cat. No. 6401.0, Canberra. Australian Institute of Health and Welfare. Nursing and midwifery labour force 2005, National health labour force series 2008; No 39; AIHW, Canberra.

Benham L. The labor market for registered nurses: a three-equation model. Review of Economics and Statistics 1971; 53; 246-252.

Birch E. Studies of the Labour Supply of Australian Women: What have we Learned? Economic Record 2005; 81; 65-84.

Blundell R, MaCurdy T. Labor supply: a review of alternative approaches. In: Ashenfelter OC Card D (Eds) Handbook of Labor Economics, vol. 3. North-Holland: Amsterdam; 1999. p. 1559-1695.

Breunig R, Gong X, King A. Partnered Women's Labour Supply and Child-Care Costs in Australia: Measurement Error and the Child-Care Price. Economic Record 2012; 88 (s1); 5169.

Chiha Y, Link C. The shortage of registered nurses and some new estimates of the effects of wages on registered nurses labour supply: a look at the past and a preview of the 21st century. Health Policy 2003; 64; 349-375.

Clark A. What really matters in a job? Hedonic measurement using quit data. Labour Economics 2001; 8; 223-242.

Cook A, Gaynor M, Stephens M, Taylor L. The Effect of Hospital Nurse Staffing on Patient Health Outcomes: Evidence from California’s Minimum Staffing Regulation. NBER Working Paper 2010; No. 16077. 
Creedy J, Duncan A. Behavioural Microsimulation with Labour Supply Responses. Journal of Economic Surveys 2002; 16; 1-39.

Di Tommaso M, Strom S, Saether E. Nurses wanted: Is the job too harsh or is the wage too low? Journal of Health Economics 2009; 28; 748-757.

Dockery AM, Barns A. Who'd be a Nurse? Some Evidence on Career Choice in Australia. Australian Bulletin of Labour 2005; 31; 350-383.

Hotz VJ, Scholz JK. The earned income tax credit. In: Moffitt R (Ed) Means-Tested Transfer Programs in the United States, The University of Chicago Press: Chicago; 2003. p 141-197.

Ikenwilo D, Scott A. The effects of pay and job satisfaction on the labour supply of hospital consultants. Health Economics 2007; 16; 1303-1318.

Kalb G. Modelling Labour Supply Responses in Australia and New Zealand. In: Claus I, Gemmell N, Harding M, White D (Eds) Tax Reform in Open Economies: International and Country Perspectives. Edward Elgar: Cheltenham; 2010. p. 166-193.

Kane, RL, Shamliyan TA, Mueller C, Duval S, Wilt TJ. The Association of Registered Nurse Staffing Levels and Patient Outcomes: Systematic Review and Meta-Analysis. Medical Care 2007; 45; 1195-1204.

Keane M, Moffitt R. A Structural Model of Multiple Welfare Program Participation and Labor Supply. International Economic Review 1998; 39(3); 553-589.

Killingsworth MR. Labor Supply. Cambridge University Press: New York; 1983.

Kornstad T, Thoresen TO. A Discrete Choice Model for Labor Supply and Child Care. Journal of Population Economics 2007; 20 (4); 781-803.

Lagarde M, Blaauw D. A review of the application and contribution of discrete choice experiments to inform human resources policy interventions. Human Resources and Health 2009; 7; 62-71.

Lagarde M. Choosing to care: the determinants of nurses' job preferences in South Africa. Health Services Research Unit, London School of Hygiene and Tropical Medicine, University of London: London; 2010; PhD (unpublished manuscript). 
Lankshear AJ, Sheldon TA, Maynard A. Nurse Staffing and Healthcare Outcomes: A Systematic Review of the International Research Evidence. Advances in Nursing Science 2005; 28; 163-174.

Link C. Labour supply behavior of registered nurses. Research in Labor Economics 1992; 13; 287-320.

Link C, Settle R. Labour supply responses of married professional nurses: new evidence. Southern Economic Journal 1979; 41; 649-656.

Link C, Settle R. Wage incentives and married professional nurses: a case of backward bending supply? Economic Inquiry 1981a; 19; 144-156.

Link C, Settle R. A simultaneous-equation model of labor supply, fertility and earnings of married women: the case of registered nurses. Southern Economic Journal 1981b; 47; 977988.

Link C, Settle R. Labour supply responses of licensed practical nurses: a partial solution to a nurse shortage. Journal of Economics and Business 1985; 37; 49-57.

Maddala, GS. Limited Dependent and Qualitative Variables in Econometrics. Cambridge University Press: New York; 1983.

Munasinghe L, Reif T, Henriques A. Gender gap in wage returns to job tenure and experience. Labour Economics 2008; 15; 1296- 1316.

Phillips V. Participation, hours of work and discontinuities in the supply function. Journal of Health Economics 1995; 14; 567-582.

Ribeiro EP. Asymmetric labour supply. Empirical Economics 2001; 26; 183-197.

Rice N. The labour supply of nurses in the UK: evidence from the British Household Panel Study. HEDG Working Paper 2005; 05/10; York.

Shields M. Addressing Nurse Shortages: What Can Policy Makers Learn From The Econometric Evidence On Nurse Labour Supply. The Economic Journal 2004; 114; F464F498. 
Shields M, Ward M. Improving nurse retention in the National Health Service in England: the impact of job satisfaction in intentions to quit. Journal of Health Economics 2001; 20; 677701.

Skatun D, Antonazzo E, Scott A, Elliott R. The supply of qualified nurses: a classical model of labour supply. Applied Economics 2005; 37; 57-65.

Sloan F, Richupan S. Short-run supply responses of professional nurses: a microanalysis. Journal of Human Resources 1975; 10; 241-257.

Van Soest A. Structural Models of Family Labor Supply: A Discrete Choice Approach. The Journal of Human Resources 1995; 30; 63-88.

Varian, H. Microeconomic Analysis, 3rd edition; W.W. Norton \& Company: London, 1992. World Health Organisation. The World Health Report 2006. Working Together for Health. World Health Organisation; Geneva, 2006. 
Table 1 Person-year-observations by shift type/occupation and hours worked

\begin{tabular}{lcccc}
\hline \multicolumn{4}{c}{ Occupation/shift type } \\
\hline Hours worked: & Nursing: day & Nursing: night & Nursing: irregular & Outside nursing \\
\hline 4-25 hours & 209 & 73 & 328 & 300 \\
26-37 hours & 171 & 111 & 373 & 250 \\
$38+$ hours & 262 & 58 & 456 & 525 \\
\hline
\end{tabular}


Table 2a Descriptive Statistics

\begin{tabular}{|c|c|c|}
\hline & $\begin{array}{l}\text { Nursing } \\
\text { qualification } \\
\text { holders }\end{array}$ & $\begin{array}{l}\text { Working in } \\
\text { nursing } \\
\text { occupations }\end{array}$ \\
\hline & \multicolumn{2}{|c|}{ Mean (Std. Dev.) } \\
\hline Female & $90.66 \%$ & $91.52 \%$ \\
\hline Age (in years) & $44.9(10.8)$ & $42.4(10.6)$ \\
\hline Holds a Bachelor Degree & $47.68 \%$ & $55.07 \%$ \\
\hline Holds a Bachelor Degree in Nursing & $19.21 \%$ & $27.00 \%$ \\
\hline Working as Registered Nurse or Midwife & $38.09 \%$ & $74.13 \%$ \\
\hline Working as Enrolled Nurse or Mothercraft Nurse & $6.07 \%$ & $11.81 \%$ \\
\hline Working as a Nursing Support or Personal Care Worker & $7.22 \%$ & $14.06 \%$ \\
\hline Number of Hours Worked Per Week & $25.74(17.37)$ & $31.93(11.12)$ \\
\hline \multicolumn{3}{|l|}{ Family Situation } \\
\hline Has Child $<=4$ Years & $10.42 \%$ & $12.40 \%$ \\
\hline Has Partner & $68.00 \%$ & $67.91 \%$ \\
\hline Has Child $<=4$ Years and No Partner & $1.86 \%$ & $2.01 \%$ \\
\hline \multicolumn{3}{|l|}{ If Partner } \\
\hline Partner is Employed & $81.75 \%$ & $88.31 \%$ \\
\hline Partner's Annual Net Income (in 10,000 AUD) & $4.75(3.09)$ & $4.80(2.97)$ \\
\hline Partner Holds a Bachelor Degree & $39.50 \%$ & $41.13 \%$ \\
\hline \multicolumn{3}{|l|}{ Personality Variables (scale 0-7) } \\
\hline Extroversion & $4.56(1.08)$ & $4.56(1.03)$ \\
\hline Emotional Stability & $5.23(1.06)$ & $5.16(1.03)$ \\
\hline Agreeableness & $5.68(0.77)$ & $5.71(0.75)$ \\
\hline Openness to New Experiences & $4.28(0.98)$ & $4.14(0.94)$ \\
\hline Conscientiousness & $5.29(1.01)$ & $5.25(1.03)$ \\
\hline \multicolumn{3}{|l|}{ Social Relationships } \\
\hline $\begin{array}{l}\text { Satisfaction with Relationship to Partner (0: completely } \\
\text { dissatisfied-10: completely satisfied) }\end{array}$ & $8.02(1.71)$ & $7.97(1.70)$ \\
\hline $\begin{array}{l}\text { Often Needs Help But Can't Get It (0: Strongly Disagree, 7: } \\
\text { Strongly Agree) }\end{array}$ & $2.32(1.49)$ & $2.32(1.45)$ \\
\hline \# person-year observations & 3972 & \\
\hline \# p-y obs., not employed & 856 & \\
\hline \# p-y obs., employed in non-nursing & 1075 & \\
\hline \# p-y obs., employed in nursing, <38hrs/week & 1265 & \\
\hline \# p-y obs., employed in nursing, >=38hrs/week & 776 & \\
\hline \# person observations & 696 & \\
\hline \# p obs., not employed & 260 & \\
\hline \# p obs., employed in non-nursing & 293 & \\
\hline \# p obs., employed in nursing, <38hrs/week & 367 & \\
\hline \# p obs., employed in nursing, >=38hrs/week & 259 & \\
\hline \# person-year observations & & 2041 \\
\hline \# p-y obs., day shifts & & 642 \\
\hline \# p-y obs., night shifts & & 242 \\
\hline \# p-y obs., irregular shifts & & 1157 \\
\hline \# person observations & & 474 \\
\hline \# p obs., day shifts & & 234 \\
\hline \# p obs., night shifts & & 98 \\
\hline \# p obs., irregular shifts & & 343 \\
\hline
\end{tabular}


Table 2b Descriptive Statistics - Predicted Wages

\begin{tabular}{llllll}
\hline & $\begin{array}{l}\text { Out of the } \\
\text { Labour Force }\end{array}$ & $\begin{array}{l}\text { Working in } \\
\text { non-nursing }\end{array}$ & $\begin{array}{l}\text { Working in } \\
\text { nursing, day } \\
\text { shifts }\end{array}$ & $\begin{array}{l}\text { Working in } \\
\text { nursing, night } \\
\text { shifts }\end{array}$ & $\begin{array}{l}\text { Working in } \\
\text { nursing, } \\
\text { irregular } \\
\text { shifts }\end{array}$ \\
\hline \multicolumn{1}{l}{ Predicted wage } & Mean (Std. Dev.) & & & \\
\hline in nursing, day shifts & $32.22(8.63)$ & $33.53(8.41)$ & $39.06(8.53)$ & $36.05(9.46)$ & $37.78(8.56)$ \\
in nursing, night shifts & $35.17(10.52)$ & $36.77(10.25)$ & $42.87(10.18)$ & $39.03(11.35)$ & $41.59(10.05)$ \\
in nursing, irregular shifts & $34.68(9.14)$ & $36.08(8.90)$ & $41.76(8.97)$ & $38.53(9.95)$ & $40.48(8.95)$ \\
in non-nursing & $43.06(8.90)$ & $48.30(9.37)$ & $47.58(10.28)$ & $43.53(8.04)$ & $47.70(9.31)$ \\
\hline
\end{tabular}

Notes: Predicted wages are in AUD\$/hour, adjusted for inflation to 2009 prices. 
Table 3 Structural Model of Labour Supply, Estimation of the Preference Parameters of the Utility Function

\begin{tabular}{|c|c|c|c|c|c|}
\hline \multicolumn{6}{|l|}{ Model (1) } \\
\hline \multicolumn{6}{|c|}{$\mathrm{U}=\mathrm{F}(\mathrm{B})=\mathrm{F}(\mathrm{w}, \mathrm{h}, \mathrm{hn}, \mathrm{hi})$} \\
\hline Variable & Coeff. & Std. Err. & & $\begin{array}{l}\text { 95\% -Confid } \\
\text { lower bound }\end{array}$ & $\begin{array}{l}\text { ence Interval } \\
\text { upper bound }\end{array}$ \\
\hline income (weekly net income in 1,000 AUD) & 7.653 & 0.833 & ** & 6.020 & 9.285 \\
\hline income $^{2}$ & -0.942 & 0.337 & $* *$ & -1.602 & -0.282 \\
\hline hours (non-nursing) & -0.236 & 0.020 & ** & -0.274 & -0.198 \\
\hline hours (non-nursing) ${ }^{2}$ & 0.002 & 0.000 & $* *$ & 0.001 & 0.003 \\
\hline income * hours (non-nursing) & 0.022 & 0.014 & & -0.004 & 0.049 \\
\hline hours (day) & -0.219 & 0.016 & ** & -0.252 & -0.187 \\
\hline hours (day) $)^{2}$ & 0.002 & 0.000 & $* *$ & 0.001 & 0.002 \\
\hline income* hours (day) & 0.020 & 0.010 & $\circ$ & -0.001 & 0.040 \\
\hline hours (night) & -0.265 & 0.024 & $* *$ & -0.311 & -0.218 \\
\hline hours (night) ${ }^{2}$ & 0.002 & 0.000 & $* *$ & 0.001 & 0.003 \\
\hline income* hours (night) & 0.017 & 0.017 & & -0.017 & 0.051 \\
\hline hours (irregular) & -0.171 & 0.017 & $* *$ & -0.204 & -0.139 \\
\hline hours (irregular) ${ }^{2}$ & 0.001 & 0.000 & $* *$ & 0.001 & 0.002 \\
\hline income* hours (irregular) & 0.009 & 0.012 & & -0.014 & 0.033 \\
\hline \# observations & 3972 & & & & \\
\hline \# person observations & 696 & & & & \\
\hline log-Likelihood & -8991.1885 & & & & \\
\hline Wald-Test of Model Significance $(\chi 2(d F))$ & $507.43(14)$ & & & ** & \\
\hline \multicolumn{6}{|c|}{ Marginal Effects } \\
\hline Variable & Marg. Eff. & Std. Err. & & & \\
\hline income & 5.347 & 0.477 & $* *$ & 4.412 & 6.282 \\
\hline hours (non-nursing) & -0.175 & 0.013 & $* *$ & -0.200 & -0.150 \\
\hline hours (day) & -0.163 & 0.011 & $* *$ & -0.185 & -0.141 \\
\hline hours (night) & -0.207 & 0.014 & ** & -0.234 & -0.180 \\
\hline hours (irregular) & -0.138 & 0.011 & $* *$ & -0.160 & -0.116 \\
\hline
\end{tabular}

Notes: **, * and ${ }^{\circ}$ indicate statistical significance at the 1, 5 and 10 percent level. 
Table 4 Structural Model of Labour Supply, Estimation of the Preference Parameters of the Utility Function by Groups

\section{Model (2)}

U= F(Income, Hours(non-nursing), Hours(day), Hours(night), Hours(irregular), Age, Children, Partner, Bachelor Degree)

\begin{tabular}{|c|c|c|c|}
\hline \multicolumn{4}{|l|}{ Model (1), as in Table 3, plus Interactions: } \\
\hline Income times ... & & & \\
\hline Age (1=upper $50^{\text {th }}$ percentile ) & 2.146 & 1.100 & $\circ$ \\
\hline Children <=4 years ( $1=$ yes) & -2.357 & 1.063 & * \\
\hline Has Partner (1=yes) & 0.421 & 1.205 & \\
\hline Holds Bachelor Degree (1=yes) & 4.294 & 1.154 & $* *$ \\
\hline Hours(non-nursing) times ... & & & \\
\hline Age (1=upper $50^{\text {th }}$ percentile ) & -0.057 & 0.021 & $* *$ \\
\hline Children <=4 years ( $1=$ yes) & 0.020 & 0.021 & \\
\hline Has Partner (1=yes) & -0.015 & 0.022 & \\
\hline Holds Bachelor Degree (1=yes) & -0.092 & 0.024 & $* *$ \\
\hline Hours(day) times... & & & \\
\hline Age (1=upper $50^{\text {th }}$ percentile ) & -0.060 & 0.018 & ** \\
\hline Children <=4 years (1=yes) & 0.020 & 0.017 & \\
\hline Has Partner (1=yes) & -0.016 & 0.017 & \\
\hline Holds Bachelor Degree (1=yes) & -0.054 & 0.018 & $* *$ \\
\hline Hours(night) times... & & & \\
\hline Age (1=upper $50^{\text {th }}$ percentile $)$ & -0.058 & 0.022 & ** \\
\hline Children <=4 years (1=yes) & 0.030 & 0.020 & \\
\hline Has Partner (1=yes) & -0.014 & 0.023 & \\
\hline Holds Bachelor Degree (1=yes) & -0.097 & 0.023 & $* *$ \\
\hline Hours(irregular) times... & & & \\
\hline Age ( $1=$ upper $50^{\text {th }}$ percentile $)$ & -0.074 & 0.020 & ** \\
\hline Children $<=4$ years $(1=$ yes $)$ & 0.014 & 0.018 & \\
\hline Has Partner (1=yes) & -0.013 & 0.019 & \\
\hline Holds Bachelor Degree (1=yes) & -0.050 & 0.020 & $* *$ \\
\hline $\begin{array}{l}\text { Wald-Tests of Joint Significance } \\
\text { Interactions: Income, Hours(non-nursing), } \\
\text { Hours(day),Hours(night), Hours (irregular) times:... }\end{array}$ & $\chi^{2}(\mathrm{dF})$ & p-value & \\
\hline Age & $41.18(5)$ & 0.000 & $* *$ \\
\hline Children $<=4$ years & $31.56(5)$ & 0.000 & $* *$ \\
\hline Has Partner & $2.64(5)$ & 0.756 & \\
\hline Holds Bachelor Degree & $50.65(5)$ & 0.000 & $* *$ \\
\hline
\end{tabular}

Notes: ** * and ${ }^{\circ}$ indicate statistical significance at the 1, 5 and 10 percent level. The standard errors were bootstrapped with 100 draws from the original sample. Model 2 is estimated on the full sample (3,974 observations). 
Table 5 Model Performance: Observed Frequencies and Average Predicted Probabilities of Shift Types and Working Hours

\begin{tabular}{|c|l|ll|ll|}
\hline \multirow{2}{*}{ Alternative: } & & \multicolumn{2}{|l|}{ Specification (1) } & \multicolumn{2}{l|}{ Specification (2) } \\
& Observed & \multicolumn{2}{|l|}{$\begin{array}{l}\text { Predicted } \\
\text { Probability }\end{array}$} & Probability & Ratio \\
Probability & Ratio \\
\hline No Employment & $21.55 \%$ & $21.17 \%$ & 0.98 & $21.18 \%$ & 0.98 \\
\hline Day Shift, 4-26 hours & $5.26 \%$ & $5.33 \%$ & 1.01 & $5.34 \%$ & 1.01 \\
Day Shift, 26-37 hours & $4.31 \%$ & $4.22 \%$ & 0.98 & $4.21 \%$ & 0.98 \\
Day Shift, >=38 hours & $6.60 \%$ & $6.63 \%$ & 1.01 & $6.64 \%$ & 1.01 \\
Day Shift & $16.16 \%$ & $16.18 \%$ & 1.00 & $16.19 \%$ & 1.00 \\
\hline Night Shift, 4-26 hours & $1.84 \%$ & $2.85 \%$ & 1.55 & $2.86 \%$ & 1.56 \\
Night Shift, 26-37 hours & $2.79 \%$ & $1.56 \%$ & 0.56 & $1.55 \%$ & 0.56 \\
Night Shift, >=38 hours & $1.46 \%$ & $1.97 \%$ & 1.35 & $1.97 \%$ & 1.35 \\
Night Shift & $6.09 \%$ & $6.38 \%$ & 1.05 & $6.38 \%$ & 1.05 \\
\hline Irregular Shift, 4-26 hours & $8.26 \%$ & $9.10 \%$ & 1.10 & $9.10 \%$ & 1.10 \\
Irregular Shift, 26-37 hours & $9.39 \%$ & $8.36 \%$ & 0.89 & $8.36 \%$ & 0.89 \\
Irregular Shift, >=38 hours & $11.48 \%$ & $11.90 \%$ & 1.04 & $11.90 \%$ & 1.04 \\
Irregular Shift & $29.13 \%$ & $29.37 \%$ & 1.01 & $29.37 \%$ & 1.01 \\
\hline Other Occupation, 4-25 hours & $7.55 \%$ & $6.97 \%$ & 0.92 & $6.95 \%$ & 0.92 \\
Other Occupation, 26-37 hours & $6.29 \%$ & $7.01 \%$ & 1.11 & $7.03 \%$ & 1.12 \\
Other Occupation, >=38 hours & $13.22 \%$ & $12.92 \%$ & 0.98 & $12.92 \%$ & 0.98 \\
Other Occupation & $27.06 \%$ & $26.90 \%$ & 0.99 & $26.90 \%$ & 0.99 \\
\hline
\end{tabular}


Table 6a Predicted Changes in Probability of Shift type and Expected Working Hours for Changes in Income and Wages

\begin{tabular}{|c|c|c|c|c|c|c|c|c|c|c|c|c|}
\hline \multirow[b]{3}{*}{$\Delta$ Prob (No Employment) (in \%-points) } & \multicolumn{3}{|c|}{$\begin{array}{l}\text { Increase in other } \\
\text { net income by } 1 \%\end{array}$} & \multicolumn{3}{|c|}{$\begin{array}{l}\text { Increase in gross } \\
\text { wage for all } \\
\text { occupations by } 1 \%\end{array}$} & \multicolumn{3}{|c|}{$\begin{array}{l}\text { Increase in gross } \\
\text { wage for nursing } \\
\text { occupations by } 1 \%\end{array}$} & \multicolumn{3}{|c|}{$\begin{array}{l}\text { Increase in gross wage } \\
\text { for non-nursing } \\
\text { occupations by } 1 \%\end{array}$} \\
\hline & Pred. & Std. Err. & & Pred. & Std. Err. & & Pred. & Std. Err. & & Pred. & Std. Err. & \\
\hline & 0.061 & 0.012 & $* *$ & -0.377 & 0.047 & $* *$ & -0.223 & 0.028 & $* *$ & -0.157 & 0.023 & $* *$ \\
\hline$\Delta$ Prob (Day Shift) (in \%-points) & 0.008 & 0.008 & & 0.049 & 0.013 & $* *$ & 0.186 & 0.024 & $* *$ & -0.137 & 0.018 & $* *$ \\
\hline$\Delta$ Prob (Night Shift) (in \%-points) & -0.002 & 0.007 & & 0.011 & 0.009 & & 0.067 & 0.011 & $* *$ & -0.056 & 0.009 & $* *$ \\
\hline$\Delta$ Prob (Irregular Shift) (in \%-points) & -0.045 & 0.009 & $* *$ & 0.060 & 0.022 & $* *$ & 0.330 & 0.042 & $* *$ & -0.271 & 0.035 & $* *$ \\
\hline$\Delta$ Prob (Other Occupation) (in \%-points) & -0.022 & 0.010 & $*$ & 0.257 & 0.034 & $* *$ & -0.360 & 0.040 & $* *$ & 0.621 & 0.069 & ** \\
\hline$\Delta \mathrm{E}($ Hours in Day Shift $\mid$ Day Shift $)$ & -0.007 & 0.003 & $*$ & 0.081 & 0.009 & $* *$ & 0.081 & 0.009 & $* *$ & 0 & 0 & \\
\hline$\Delta \mathrm{E}$ (Hours in Night Shift| Night Shift) & -0.011 & 0.006 & $\circ$ & 0.080 & 0.012 & $* *$ & 0.080 & 0.012 & ** & 0 & 0 & \\
\hline$\Delta \mathrm{E}$ (Hours in Irregular Shift| Irregular Shift) & -0.016 & 0.003 & $* *$ & 0.069 & 0.009 & $* *$ & 0.069 & 0.009 & $* *$ & 0 & 0 & \\
\hline$\Delta \mathrm{E}$ (Hours in Other Occupation| Other Occupation) & -0.010 & 0.003 & $* *$ & 0.085 & 0.011 & $* *$ & 0 & 0 & & 0.085 & 0.011 & $* *$ \\
\hline Elasticity (Hours in Day Shift| Day Shift) & -0.021 & 0.011 & $*$ & 0.255 & 0.030 & ** & 0.255 & 0.030 & $* *$ & 0 & 0 & \\
\hline Elasticity (Hours in Night Shift| Night Shift) & -0.039 & 0.025 & & 0.276 & 0.044 & $* *$ & 0.276 & 0.044 & $* *$ & 0 & 0 & \\
\hline Elasticity (Hours in Irregular Shift| Irregular Shift) & -0.052 & 0.011 & $* *$ & 0.214 & 0.029 & $* *$ & 0.214 & 0.029 & $* *$ & 0 & 0 & \\
\hline Elasticity (Hours in Other Occupation| Other Occupation) & -0.030 & 0.010 & $* *$ & 0.255 & 0.035 & $* *$ & 0 & 0 & & 0.255 & 0.035 & $* *$ \\
\hline$\Delta \mathrm{E}$ (Hours in Nursing Occupation| Nursing Occupation) & -0.012 & 0.003 & $* *$ & 0.074 & 0.009 & $* *$ & 0.074 & 0.009 & $* *$ & 0 & 0 & \\
\hline $\begin{array}{l}\text { Elasticity (Hours in Nursing Occupation| Nursing } \\
\text { Occupation) }\end{array}$ & -0.038 & 0.010 & $* *$ & 0.236 & 0.029 & ** & 0.236 & 0.029 & $* *$ & 0 & 0 & \\
\hline$\Delta \mathrm{E}$ (Hours in Nursing Occupation) & -0.018 & 0.005 & $* *$ & 0.077 & 0.012 & $* *$ & 0.227 & 0.024 & $* *$ & -0.151 & 0.018 & ** \\
\hline Elasticity (Hours in Nursing Occupation) & -0.112 & 0.038 & $* *$ & 0.444 & 0.078 & $* *$ & 1.374 & 0.168 & $* *$ & -0.929 & 0.126 & $* *$ \\
\hline$\Delta \mathrm{E}($ Total Hours $)$ & -0.029 & 0.005 & $* *$ & 0.187 & 0.022 & $* *$ & 0.103 & 0.013 & $* *$ & 0.086 & 0.012 & $* *$ \\
\hline Elasticity of Total Hours & -0.121 & 0.028 & $* *$ & 0.752 & 0.105 & $* *$ & 0.412 & 0.062 & $* *$ & 0.347 & 0.057 & $* *$ \\
\hline
\end{tabular}


Table 6b Predicted Changes in Probability of Shift type and Expected Working Hours for Changes in Wages by Shift

\begin{tabular}{|c|c|c|c|c|c|c|c|c|c|}
\hline & \multicolumn{2}{|c|}{$\begin{array}{l}\text { Increase in gross } \\
\text { wage (day shifts) by } \\
1 \%\end{array}$} & & \multicolumn{2}{|c|}{$\begin{array}{l}\text { Increase in gross } \\
\text { wage (night shifts) by } \\
1 \%\end{array}$} & & \multicolumn{3}{|c|}{$\begin{array}{l}\text { Increase in gross } \\
\text { wage (irregular } \\
\text { shifts) by } 1 \%\end{array}$} \\
\hline & Pred. & Std. Err. & & Pred. & Std. Err. & & Pred. & Std. Err. & \\
\hline$\Delta$ Prob (No Employment) (in \%-points) & -0.072 & 0.011 & ** & -0.027 & 0.005 & $* *$ & -0.126 & 0.018 & $* *$ \\
\hline$\Delta$ Prob (Day Shift) (in \%-points) & 0.354 & 0.046 & $* *$ & -0.029 & 0.004 & $* *$ & -0.137 & 0.022 & $* *$ \\
\hline$\Delta$ Prob (Night Shift) (in \%-points) & -0.030 & 0.004 & $* *$ & 0.155 & 0.022 & $* *$ & -0.057 & 0.010 & $* *$ \\
\hline$\Delta$ Prob (Irregular Shift) (in \%-points) & -0.142 & 0.023 & $* *$ & -0.057 & 0.009 & $* *$ & 0.530 & 0.064 & $* *$ \\
\hline$\Delta$ Prob (Other Occupation) (in \%-points) & -0.110 & 0.014 & ** & -0.043 & 0.006 & $* *$ & -0.210 & 0.028 & $* *$ \\
\hline$\Delta \mathrm{E}$ (Hours in Shift with Wage Increase| Shift with Wage Increase) & 0.081 & 0.009 & ** & 0.080 & 0.012 & $* *$ & 0.069 & 0.009 & $* *$ \\
\hline $\begin{array}{l}\text { Elasticity (Hours in Shift with Wage Increase| Shift with Wage } \\
\text { Increase) }\end{array}$ & 0.255 & 0.030 & ** & 0.276 & 0.044 & $* *$ & 0.214 & 0.029 & $* *$ \\
\hline$\Delta \mathrm{E}$ (Hours in Nursing Occupation| Nursing Occupation) & 0.028 & 0.006 & ** & 0.002 & 0.003 & & 0.046 & 0.008 & ** \\
\hline Elasticity (Hours in Nursing Occupation| Nursing Occupation) & 0.087 & 0.019 & $* *$ & 0.006 & 0.010 & & 0.146 & 0.026 & $* *$ \\
\hline$\Delta \mathrm{E}$ (Hours in Shift with Wage Increase) & 0.130 & 0.018 & ** & 0.052 & 0.008 & ** & 0.196 & 0.025 & $* *$ \\
\hline Elasticity (Hours in Shift with Wage Increase) & 2.433 & 0.274 & ** & 2.589 & 0.329 & $* *$ & 1.937 & 0.231 & $* *$ \\
\hline$\Delta \mathrm{E}$ (Hours in Nursing Occupation) & 0.073 & 0.010 & ** & 0.023 & 0.004 & $* *$ & 0.133 & 0.017 & $* *$ \\
\hline Elasticity (Hours in Nursing Occupation) & 0.443 & 0.065 & ** & 0.140 & 0.026 & $* *$ & 0.802 & 0.115 & $* *$ \\
\hline
\end{tabular}

Notes: **, * and ${ }^{\circ}$ indicate statistical significance at the 1, 5 and 10 percent level. The standard errors were bootstrapped with 100 draws from the original sample. All predictions are based on the Model presented in Table 3. 
Table 7 Predicted Changes in Probability of Shift type and Expected Working Hours for Increase in Other Net Income by $1 \%$

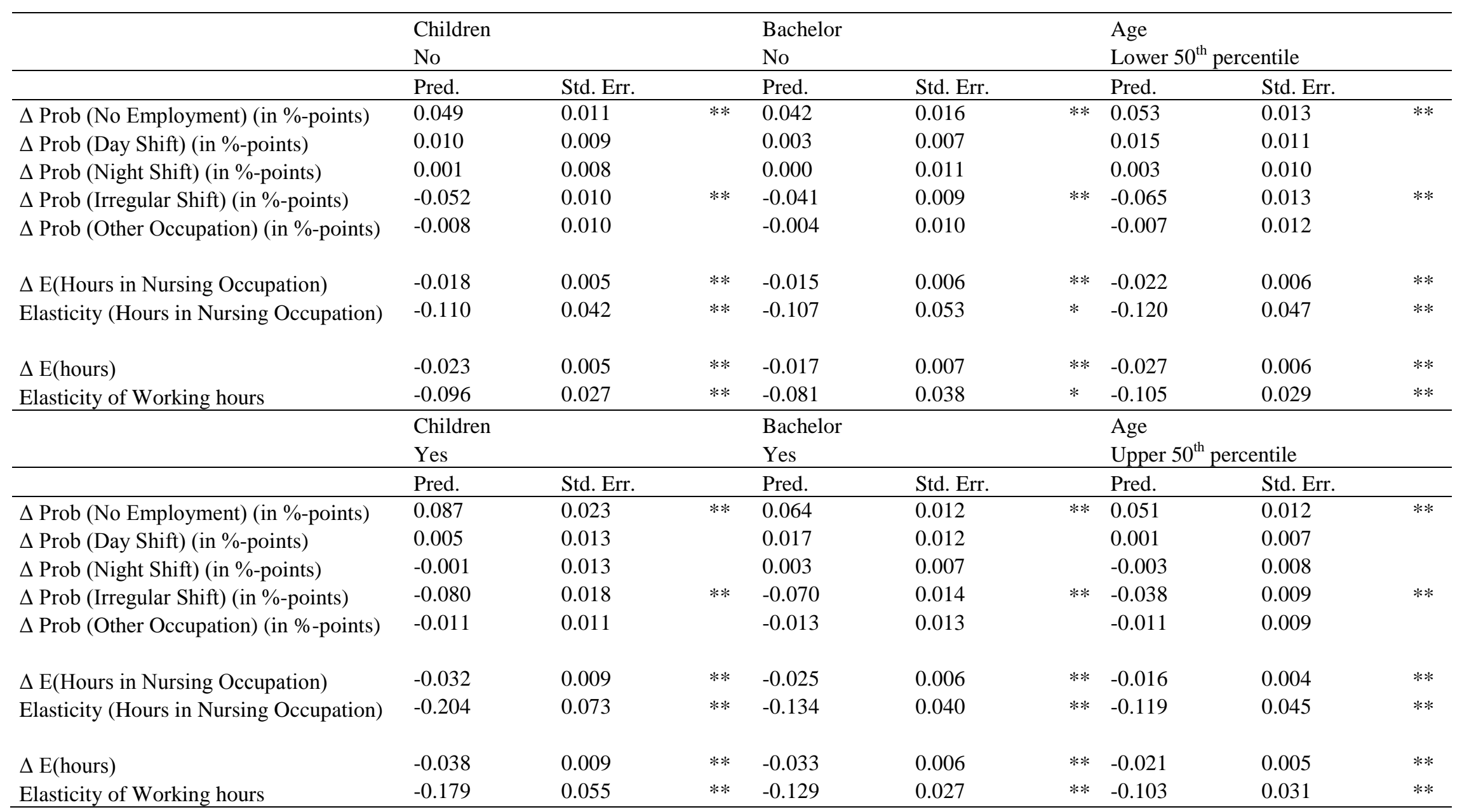

Notes: **, * and ${ }^{\circ}$ indicate statistical significance at the 1, 5 and 10 percent level. The standard errors were bootstrapped with 100 draws from the original sample.

Elasticities by Children, Bachelor Degree and Age are estimated based on Model (2) and the full sample (3,974 observations). 
Table 8 Predicted Changes in Probability of Shift type and Expected Working Hours for 1\% Increase in Gross Wages in Nursing

\begin{tabular}{|c|c|c|c|c|c|c|c|c|c|}
\hline & \multicolumn{3}{|l|}{$\begin{array}{l}\text { Children } \\
\text { No }\end{array}$} & \multicolumn{2}{|c|}{$\begin{array}{l}\text { Bachelor } \\
\text { No }\end{array}$} & & \multicolumn{3}{|c|}{$\begin{array}{l}\text { Age } \\
\text { Lower } 50^{\text {th }} \text { percentile }\end{array}$} \\
\hline & Coeff. & Std. Err. & & Coeff. & Std. Err. & & Coeff. & Std. Err. & \\
\hline$\Delta$ Prob (No Employment) (in \%-points) & -0.233 & 0.028 & $* *$ & -0.276 & 0.044 & $* *$ & -0.192 & 0.030 & $* *$ \\
\hline$\Delta$ Prob (Day Shift) (in \%-points) & 0.231 & 0.033 & $* *$ & 0.320 & 0.054 & $* *$ & 0.195 & 0.031 & $* *$ \\
\hline$\Delta$ Prob (Night Shift) (in \%-points) & 0.078 & 0.014 & $* *$ & 0.063 & 0.017 & $* *$ & 0.054 & 0.012 & ** \\
\hline$\Delta$ Prob (Irregular Shift) (in \%-points) & 0.402 & 0.047 & $* *$ & 0.589 & 0.081 & $* *$ & 0.377 & 0.059 & $* *$ \\
\hline$\Delta$ Prob (Other Occupation) (in \%-points) & -0.479 & 0.055 & $* *$ & -0.696 & 0.098 & $* *$ & -0.435 & 0.063 & ** \\
\hline$\Delta \mathrm{E}$ (Hours in Nursing Occupation) & 0.280 & 0.029 & $* *$ & 0.396 & 0.052 & $* *$ & 0.255 & 0.035 & $* *$ \\
\hline Elasticity (Hours in Nursing Occupation) & 1.700 & 0.202 & $* *$ & 2.110 & 0.327 & $* *$ & 1.332 & 0.210 & $* *$ \\
\hline$\Delta \mathrm{E}$ (hours) & 0.112 & 0.014 & $* *$ & 0.148 & 0.024 & $* *$ & 0.100 & 0.016 & ** \\
\hline \multirow[t]{3}{*}{ Elasticity of Working hours } & 0.442 & 0.062 & $* *$ & 0.546 & 0.103 & $* *$ & 0.364 & 0.064 & $* *$ \\
\hline & \multicolumn{2}{|c|}{$\begin{array}{l}\text { Children } \\
\text { Yes }\end{array}$} & & \multicolumn{2}{|c|}{$\begin{array}{l}\text { Bachelor } \\
\text { Yes }\end{array}$} & & \multicolumn{3}{|c|}{$\begin{array}{l}\text { Age } \\
\text { Upper } 50^{\text {th }} \text { percentile }\end{array}$} \\
\hline & Coeff. & Std. Err. & & Coeff. & Std. Err. & & Coeff. & Std. Err. & \\
\hline$\Delta$ Prob (No Employment) (in \%-points) & -0.228 & 0.075 & $* *$ & -0.192 & 0.034 & $* *$ & -0.296 & 0.044 & $* *$ \\
\hline$\Delta$ Prob (Day Shift) (in \%-points) & 0.158 & 0.049 & $* *$ & 0.135 & 0.028 & $* *$ & 0.268 & 0.062 & $* *$ \\
\hline$\Delta$ Prob (Night Shift) (in \%-points) & 0.046 & 0.026 & $\circ$ & 0.086 & 0.017 & $* *$ & 0.108 & 0.026 & $* *$ \\
\hline$\Delta$ Prob (Irregular Shift) (in \%-points) & 0.200 & 0.075 & $* *$ & 0.191 & 0.038 & $* *$ & 0.387 & 0.055 & ** \\
\hline$\Delta$ Prob (Other Occupation) (in \%-points) & -0.176 & 0.065 & $* *$ & -0.221 & 0.036 & $* *$ & -0.467 & 0.076 & $* *$ \\
\hline$\Delta \mathrm{E}$ (Hours in Nursing Occupation) & $\begin{array}{l}\text { 0.Table } \\
8156\end{array}$ & 0.051 & $* *$ & 0.150 & 0.023 & $* *$ & 0.286 & 0.039 & $* *$ \\
\hline Elasticity (Hours in Nursing Occupation) & 0.892 & 0.359 & $* *$ & 1.166 & 0.198 & $* *$ & 2.066 & 0.359 & $* *$ \\
\hline$\Delta \mathrm{E}$ (hours) & 0.100 & 0.032 & $* *$ & 0.076 & 0.014 & $* *$ & 0.127 & 0.019 & $* *$ \\
\hline Elasticity of Working hours & 0.425 & 0.159 & $* *$ & 0.344 & 0.073 & $* *$ & 0.562 & 0.100 & $* *$ \\
\hline
\end{tabular}

Notes: ${ }^{* *}, *$ and ${ }^{\circ}$ indicate statistical significance at the 1,5 and 10 percent level. The standard errors were bootstrapped with 100 draws from the original sample. Elasticities by Children, Bachelor Degree and Age are estimated based on Model (2) and the full sample (3,974 observations). 
Figure 1 Predicted Probability of Employment Type by Presence of Children, Partner and Partner's Annual Net Income (in AUD)

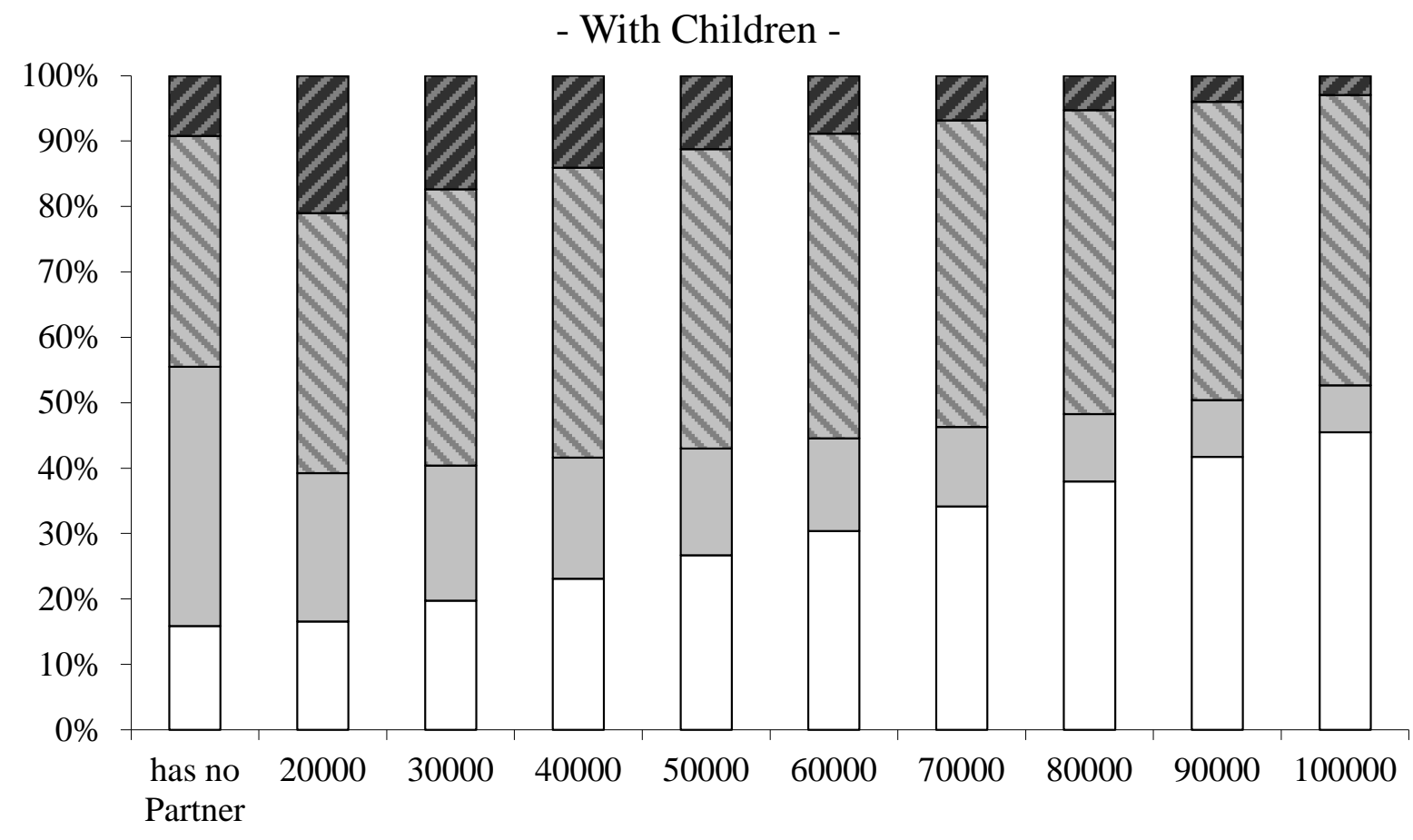

- Full-Time Nursing $\square$ Part-Time Nursing $\square$ Other Occupation $\square$ No Employment

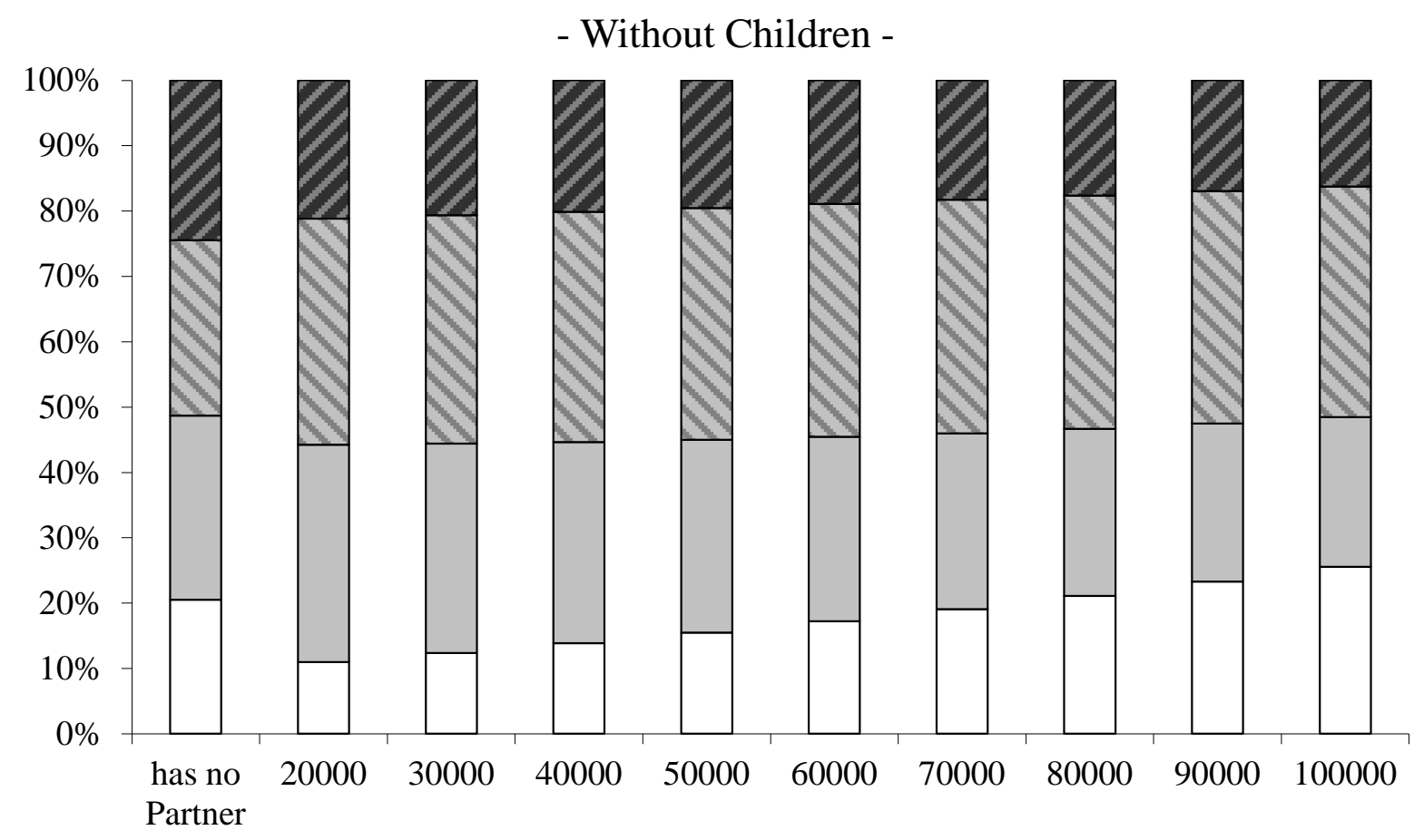

$\square$ Full-Time Nursing $\square$ Part-Time Nursing $\quad \square$ Other Occupation $\square$ No Employment 
Figure 2 Predicted Probability of Shift type by Presence of Children, Partner and

Partner's Annual Net Income (in AUD)

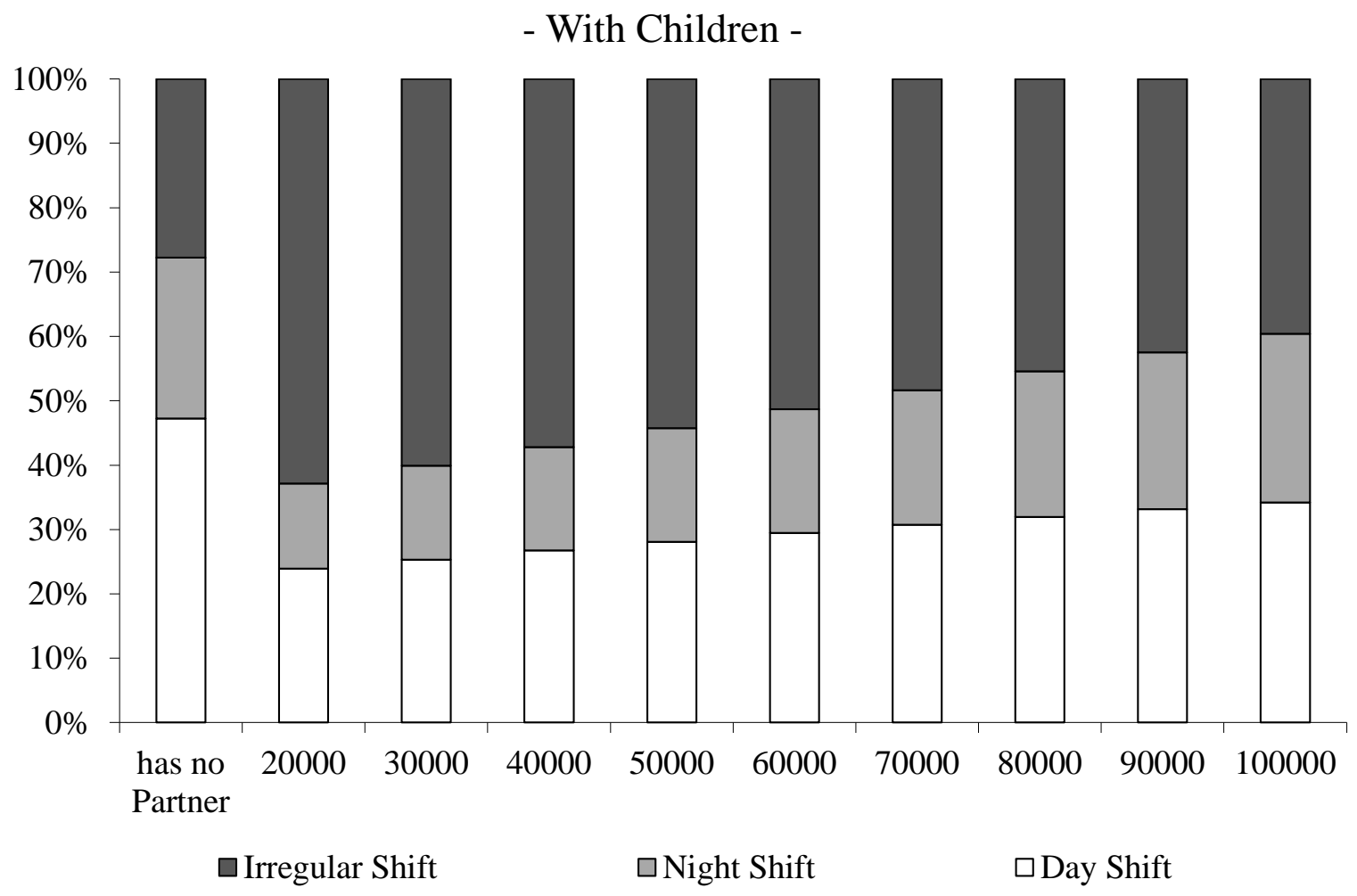

- Without Children -

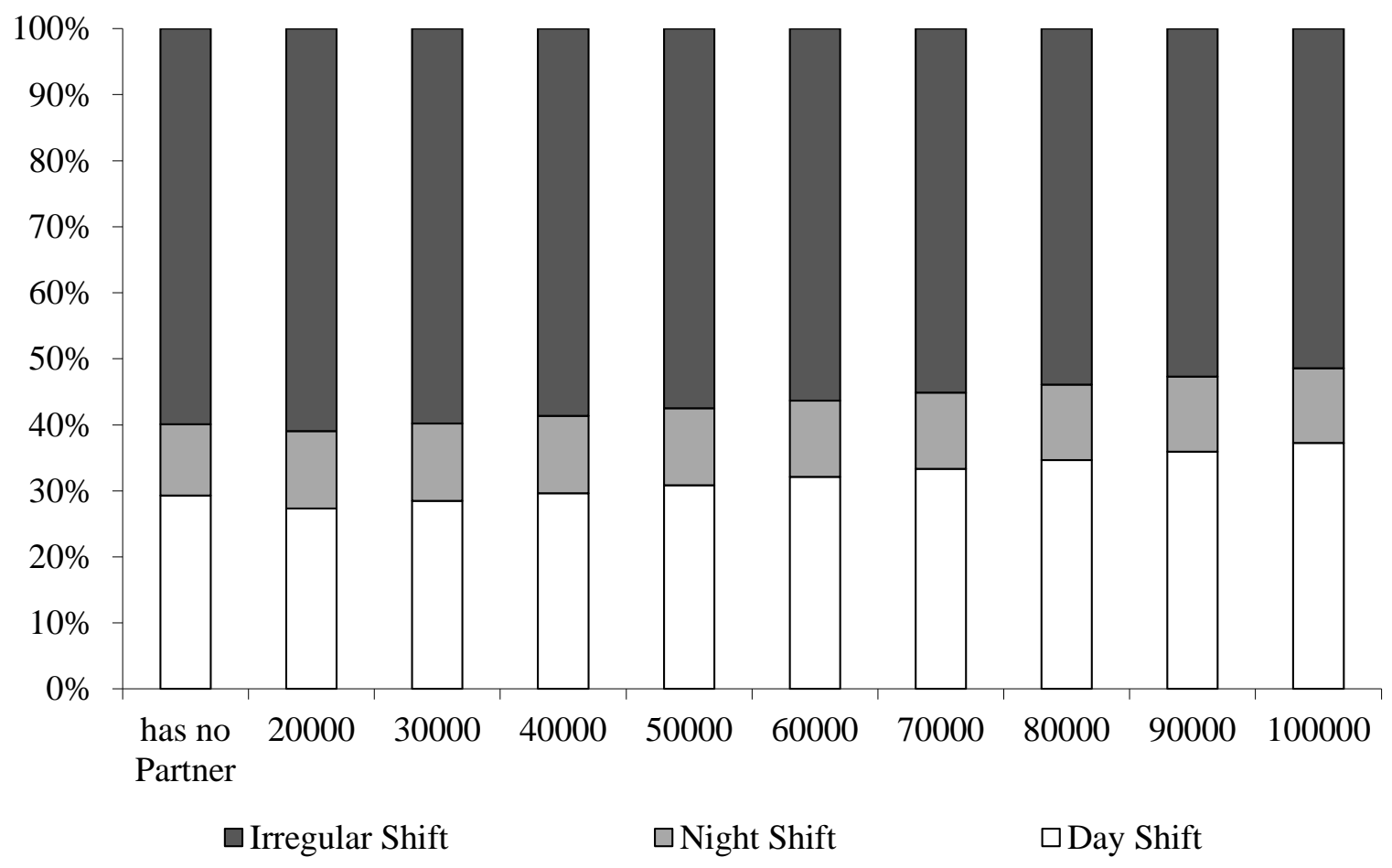


Figure 3 Distribution of Elasticities
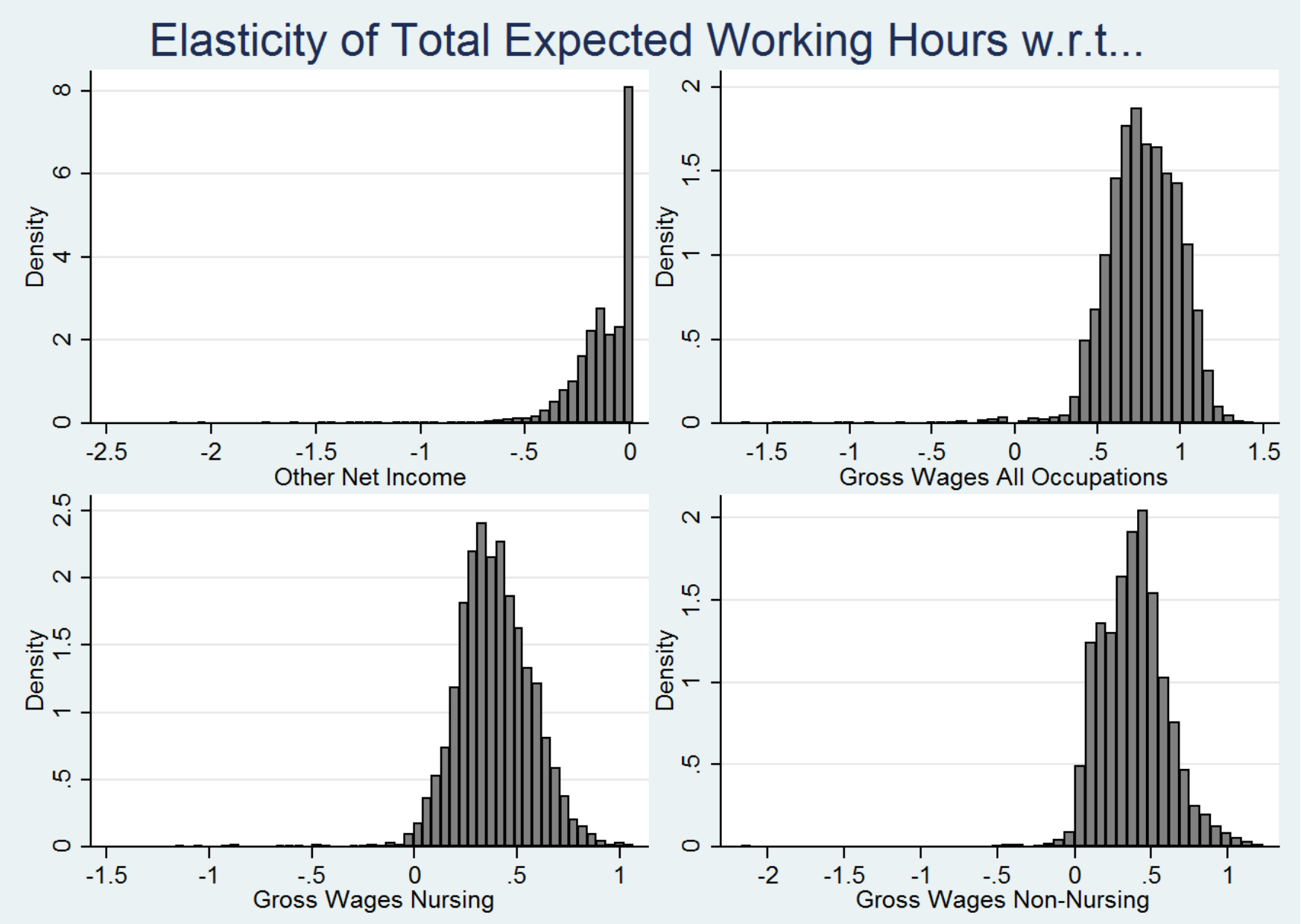
Figure 3 continued

Elasticity of Expected Working Hours in Nursing Jobs w.r.t...
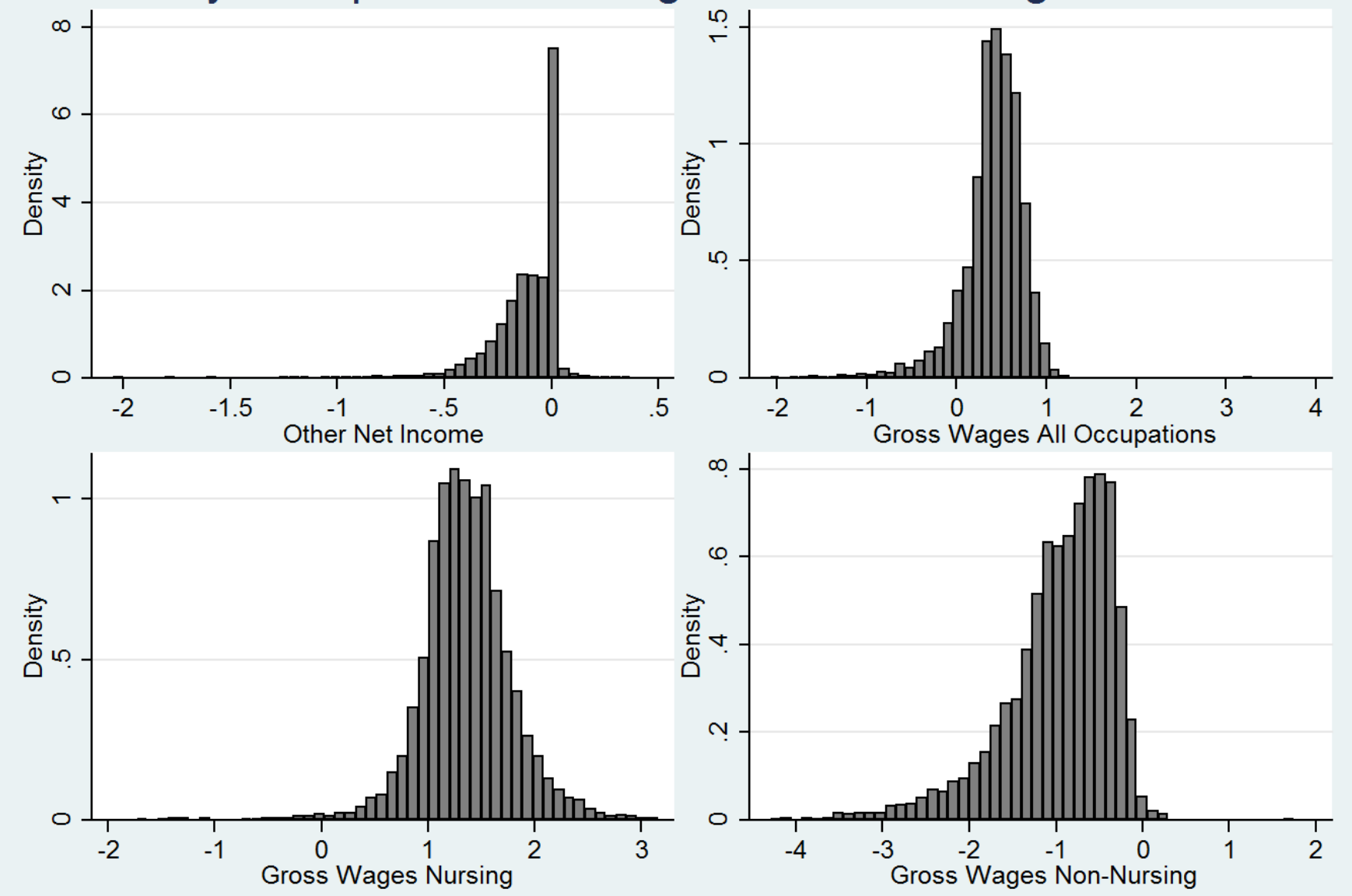


\section{Appendix A: Multinomial Logit Tables}

Table A1 Probability of Employment Type in Nursing: Multinomial Logit Model

\begin{tabular}{|c|c|c|c|c|c|c|c|c|c|c|c|c|}
\hline \multirow[b]{2}{*}{ Variable } & \multicolumn{3}{|c|}{ No Employment } & \multicolumn{3}{|c|}{ Other Occupation } & \multicolumn{2}{|c|}{ Part-Time Nursing } & \multicolumn{4}{|c|}{ Full-Time Nursing } \\
\hline & $\begin{array}{l}\text { Marg. } \\
\text { Eff. }\end{array}$ & $\begin{array}{l}\text { Std. } \\
\text { Err. }\end{array}$ & & $\begin{array}{l}\text { Marg. } \\
\text { Eff. }\end{array}$ & Std. Err. & & $\begin{array}{l}\text { Marg. } \\
\text { Eff. }\end{array}$ & Std. Err. & & $\begin{array}{l}\text { Marg. } \\
\text { Eff. }\end{array}$ & Std. Err. & \\
\hline is female & -0.014 & 0.050 & & -0.016 & 0.062 & & 0.168 & 0.046 & $* *$ & -0.118 & 0.057 & $*$ \\
\hline age & 0.085 & 0.015 & $* *$ & 0.009 & 0.014 & & -0.061 & 0.015 & $* *$ & -0.025 & 0.012 & $*$ \\
\hline holds a bachelor degree & -0.099 & 0.029 & $* *$ & -0.029 & 0.035 & & 0.027 & 0.041 & & 0.165 & 0.040 & $* *$ \\
\hline \multicolumn{13}{|l|}{ Family Situation } \\
\hline has partner & 0.090 & 0.035 & $* *$ & -0.088 & 0.051 & $\circ$ & 0.008 & 0.056 & & -0.017 & 0.039 & \\
\hline partner is employed & -0.258 & 0.038 & $* *$ & 0.152 & 0.040 & $* *$ & 0.095 & 0.047 & $*$ & 0.024 & 0.032 & \\
\hline has child <=4 years & 0.053 & 0.041 & & -0.036 & 0.041 & & 0.068 & 0.040 & $\circ$ & -0.085 & 0.026 & $* *$ \\
\hline \multicolumn{13}{|l|}{ Marginal Effect of child if... } \\
\hline no partner & -0.015 & 0.106 & & 0.047 & 0.094 & & 0.114 & 0.088 & & -0.168 & 0.040 & $* *$ \\
\hline non-employed partner & 0.124 & 0.097 & & 0.023 & 0.091 & & -0.126 & 0.089 & & 0.031 & 0.092 & \\
\hline employed partner & 0.077 & 0.051 & & -0.117 & 0.058 & $*$ & 0.052 & 0.055 & & -0.010 & 0.060 & \\
\hline partner's annual net income (in 10,000 AUD) & 0.021 & 0.006 & $* *$ & -0.013 & 0.008 & $\circ$ & 0.001 & 0.006 & & -0.011 & 0.006 & $\circ$ \\
\hline $\begin{array}{l}\text { Marginal effect of partners' income if... } \\
\text { does not have child }<=4 \text { years }\end{array}$ & 0.019 & 0.006 & $* *$ & -0.013 & 0.008 & & 0.000 & 0.006 & & -0.008 & 0.006 & \\
\hline has child $<=4$ years & 0.035 & 0.011 & $* *$ & -0.025 & 0.017 & & 0.013 & 0.015 & & -0.029 & 0.015 & $\circ$ \\
\hline partner holds a bachelor degree & -0.032 & 0.033 & & 0.031 & 0.044 & & 0.011 & 0.043 & & 0.004 & 0.037 & \\
\hline \multicolumn{13}{|c|}{ Personality Variables $\left(0=\right.$ lower $50^{\text {th }}$ percentile , $1=$ upper $50^{\text {th }}$ percentile $)$} \\
\hline Extroversion & -0.053 & 0.028 & $\circ$ & 0.045 & 0.035 & & 0.006 & 0.036 & & -0.002 & 0.027 & \\
\hline Emotional Stability & 0.009 & 0.031 & & 0.050 & 0.037 & & -0.024 & 0.036 & & -0.036 & 0.029 & \\
\hline Agreeableness & -0.015 & 0.031 & & -0.020 & 0.037 & & 0.008 & 0.037 & & 0.028 & 0.028 & \\
\hline Openness to New Experiences & 0.061 & 0.028 & * & 0.052 & 0.035 & & -0.026 & 0.034 & & -0.083 & 0.028 & $* *$ \\
\hline Conscientiousness & 0.006 & 0.029 & & -0.011 & 0.037 & & 0.002 & 0.036 & & -0.003 & 0.027 & \\
\hline \multicolumn{13}{|c|}{ Social Relationships ( $0=$ lower $50^{\text {th }}$ percentile , $1=$ upper $50^{\text {th }}$ percentile ) } \\
\hline Satisfaction with Relationship to Partner & 0.028 & 0.021 & & 0.018 & 0.030 & & -0.021 & 0.028 & & -0.024 & 0.024 & \\
\hline Feels Lack of Support when Needed & 0.014 & 0.023 & & -0.012 & 0.023 & & 0.038 & 0.027 & & -0.040 & 0.020 & $*$ \\
\hline
\end{tabular}


Table A1 - continued

\begin{tabular}{|c|c|c|c|c|c|c|c|c|c|}
\hline & Informatic & $n$ on the 1 & stimated Model: & & & & & & \\
\hline \# person-year observations & 3329 & & & & & & & & \\
\hline \# person observations & 491 & & & & & & & & \\
\hline log-Likelihood & -4078.06 & & & & & & & & \\
\hline Wald-Test of Model Significance $\left(\chi^{2}(\mathrm{dF})\right)$ & $255.90(57$ & & & $* *$ & & & & & \\
\hline Wald-Tests of Joint Significance & $\chi^{2}(\mathrm{dF})$ & p-value & \multirow{4}{*}{ Base outcome } & $\chi^{2}(\mathrm{dF})$ & p-value & & $\chi^{2}(\mathrm{dF})$ & p-value & \multirow{4}{*}{$\circ$} \\
\hline Family Situation & $65.24(8)$ & 0.00 & & $14.95(8)$ & 0.06 & $\circ$ & $9.80(8)$ & 0.28 & \\
\hline Personality Variables & $5.99(5)$ & 0.31 & & $4.53(5)$ & 0.48 & & $11.05(5)$ & 0.05 & \\
\hline Social Relationships & $0.74(2)$ & 0.69 & & $1.99(2)$ & 0.37 & & $2.22(2)$ & 0.33 & \\
\hline
\end{tabular}

Notes: **, * and ${ }^{\circ}$ indicate statistical significance at the 1, 5 and 10 percent level. The standard errors were calculated using the Delta-method. 
Table A2 Probability of Shift type in Nursing, Multinomial Logit Model, Marginal Effects

\begin{tabular}{|c|c|c|c|c|c|c|c|c|c|}
\hline \multirow[b]{2}{*}{ Variable } & \multicolumn{3}{|l|}{ Day Shift } & \multicolumn{3}{|l|}{ Night Shift } & \multicolumn{3}{|c|}{ Irregular Shift } \\
\hline & Marg. Eff. & Std. Err. & & Marg. Eff. & Std. Err. & & Marg. Eff. & Std. Err. & \\
\hline is female & 0.028 & 0.087 & & 0.043 & 0.050 & & -0.070 & 0.088 & \\
\hline age & 0.021 & 0.019 & & 0.024 & 0.015 & & -0.045 & 0.021 & $*$ \\
\hline holds a bachelor degree & 0.015 & 0.045 & & -0.111 & 0.036 & $* *$ & 0.096 & 0.047 & $*$ \\
\hline \multicolumn{10}{|l|}{ Family Situation } \\
\hline has partner & -0.002 & 0.072 & & -0.014 & 0.038 & & 0.016 & 0.073 & \\
\hline partner is employed & -0.001 & 0.067 & & -0.051 & 0.045 & & 0.052 & 0.063 & \\
\hline has child $<=4$ years & 0.021 & 0.047 & & 0.065 & 0.044 & & -0.086 & 0.048 & $\circ$ \\
\hline \multicolumn{10}{|l|}{ Marginal Effect of child if... } \\
\hline no partner & 0.150 & 0.149 & & 0.192 & 0.148 & & -0.342 & 0.088 & $* *$ \\
\hline non-employed partner & -0.140 & 0.143 & & -0.219 & 0.058 & $* *$ & 0.359 & 0.142 & $* *$ \\
\hline employed partner & -0.034 & 0.047 & & 0.037 & 0.045 & & -0.004 & 0.055 & \\
\hline partner's annual net income (in 10,000 AUD) & 0.012 & 0.007 & $\circ$ & 0.001 & 0.006 & & -0.013 & 0.007 & $\circ$ \\
\hline \multicolumn{10}{|c|}{ Marginal effect of partners' income if... } \\
\hline does not have child $<=4$ years & 0.012 & 0.007 & & 0.000 & 0.006 & & -0.011 & 0.007 & \\
\hline has child $<=4$ years & 0.012 & 0.018 & & 0.014 & 0.020 & & -0.026 & 0.019 & \\
\hline partner holds a bachelor degree & 0.017 & 0.054 & & -0.001 & 0.044 & & -0.016 & 0.054 & \\
\hline \multicolumn{10}{|c|}{ Personality Variables $\left(0=\right.$ lower $50^{\text {th }}$ percentile , $1=$ upper $50^{\text {th }}$ percentile $)$} \\
\hline Extroversion & 0.078 & 0.045 & $\circ$ & -0.019 & 0.034 & & -0.059 & 0.046 & \\
\hline Emotional Stability & -0.029 & 0.044 & & 0.029 & 0.037 & & 0.000 & 0.046 & \\
\hline Agreeableness & 0.055 & 0.046 & & 0.006 & 0.034 & & -0.061 & 0.047 & \\
\hline Openness to New Experiences & -0.117 & 0.043 & $* *$ & -0.006 & 0.033 & & 0.123 & 0.044 & $* *$ \\
\hline Conscientiousness & 0.008 & 0.044 & & -0.019 & 0.036 & & 0.012 & 0.046 & \\
\hline \multicolumn{10}{|l|}{ Social Relationships } \\
\hline Satisfaction with Relationship to Partner & -0.012 & 0.039 & & 0.023 & 0.029 & & -0.011 & 0.039 & \\
\hline Feels Lack of Support when Needed & -0.016 & 0.032 & & 0.019 & 0.022 & & -0.003 & 0.034 & \\
\hline
\end{tabular}


Table A2. - continued

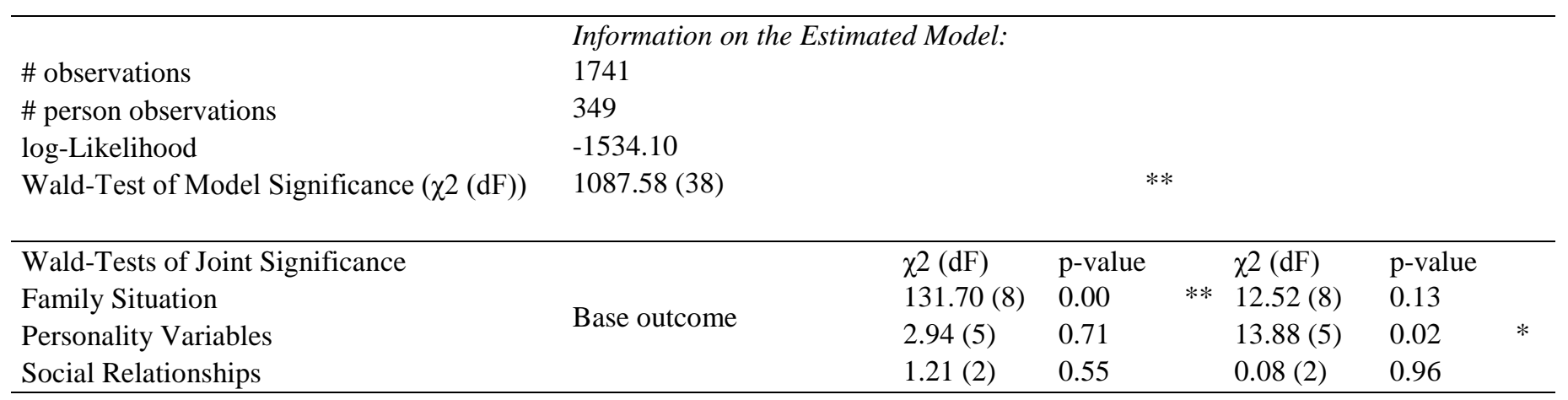

Notes: **, * and ${ }^{\circ}$ indicate statistical significance at the 1, 5 and 10 percent level. The standard errors were calculated using the Delta-method. 


\section{Appendix B: Checks of Model Performance}

As described in section 5, the average probability of choosing each of the employment types and working hours bands predicted by the model match the observed frequencies for each of the choices closely. However, this indicator of overall model performance does not tell us to what extent differences in labour market behaviour are predicted by the model, both between individuals with different characteristics as well as within individuals whose personal characteristics and expected wages vary over time.

To assess how well the model reflects variation in labour market behaviour between individuals, we compare the average predicted probability for choosing a given employment type and working hours band for the sub-sample of individuals who were observed to have chosen that alternative and the sub-sample who were observed to have chosen any other alternative. Table B1 shows the model performance for each specification.

Table B1: Average Predicted Probabilities for Choosing an Alternative, by Individual's Choice

\begin{tabular}{|c|c|c|c|c|c|c|}
\hline \multirow[b]{2}{*}{ Alternative: } & \multicolumn{6}{|c|}{ Average Predicted Probability of choosing alternative $\mathrm{j}$} \\
\hline & \begin{tabular}{|c} 
S \\
Individuals \\
choose \\
alternative $\mathrm{j}$
\end{tabular} & $\begin{array}{l}\text { ecification } \\
\text { Individual } \\
\text { choose } \\
\text { other } \\
\text { alternative }\end{array}$ & Ratio & \begin{tabular}{|c}
$\mathrm{Sp}$ \\
Individuals \\
choose \\
alternative j
\end{tabular} & $\begin{array}{l}\text { ecification } \\
\text { Individual } \\
\text { choose } \\
\text { other } \\
\text { alternative }\end{array}$ & Ratio \\
\hline No Employment & $26.76 \%$ & $19.64 \%$ & 1.36 & $29.80 \%$ & $18.81 \%$ & 1.58 \\
\hline Day Shift, 4-26 hours & $5.79 \%$ & $5.31 \%$ & 1.09 & $5.99 \%$ & $5.30 \%$ & 1.13 \\
\hline Day Shift, 26-37 hours & $4.59 \%$ & $4.20 \%$ & 1.09 & $4.70 \%$ & $4.19 \%$ & 1.12 \\
\hline Day Shift, $>=38$ hours & $8.17 \%$ & $6.52 \%$ & 1.25 & $9.23 \%$ & $6.45 \%$ & 1.43 \\
\hline Day Shift & $17.75 \%$ & $15.88 \%$ & 1.12 & $18.71 \%$ & $15.70 \%$ & 1.19 \\
\hline Night Shift, 4-26 hours & $2.96 \%$ & $2.85 \%$ & 1.04 & $3.24 \%$ & $2.85 \%$ & 1.14 \\
\hline Night Shift, 26-37 hours & $1.59 \%$ & $1.55 \%$ & 1.03 & $2.05 \%$ & $1.54 \%$ & 1.33 \\
\hline Night Shift, $>=38$ hours & $2.17 \%$ & $1.97 \%$ & 1.10 & $2.00 \%$ & $1.97 \%$ & 1.02 \\
\hline Night Shift & $6.66 \%$ & $6.36 \%$ & 1.05 & $7.71 \%$ & $6.29 \%$ & 1.23 \\
\hline Irregular Shift, 4-26 hours & $9.32 \%$ & $9.08 \%$ & 1.03 & $9.72 \%$ & $9.04 \%$ & 1.08 \\
\hline Irregular Shift, 26-37 hours & $9.20 \%$ & $8.27 \%$ & 1.11 & $10.17 \%$ & $8.18 \%$ & 1.24 \\
\hline Irregular Shift, $>=38$ hours & $14.68 \%$ & $11.54 \%$ & 1.27 & $18.02 \%$ & $11.11 \%$ & 1.62 \\
\hline Irregular Shift & $31.56 \%$ & $28.46 \%$ & 1.11 & $35.12 \%$ & $27.00 \%$ & 1.30 \\
\hline Other Occupation, 4-25 hours & $7.70 \%$ & $6.91 \%$ & 1.12 & $8.40 \%$ & $6.83 \%$ & 1.23 \\
\hline Other Occupation, 26-37 hours & $7.83 \%$ & $6.95 \%$ & 1.13 & $8.40 \%$ & $6.94 \%$ & 1.21 \\
\hline Other Occupation, $>=38$ hours & $17.90 \%$ & $12.17 \%$ & 1.47 & $18.92 \%$ & $12.00 \%$ & 1.58 \\
\hline Other Occupation & $31.14 \%$ & $25.33 \%$ & 1.23 & $33.01 \%$ & $24.63 \%$ & 1.34 \\
\hline
\end{tabular}


Specification 1 appears to reflect differences between individuals with respect to choosing non-employment, employment as a nurse or employment in other occupations well: the average predicted probabilities of choosing one of these options are considerably larger for those nursing qualification holders who were observed to have chosen this alternative than for those who were not. However, specification 1 does not reflect differences in the number of hours worked in a given shift type to the same extent. Adding additional personal characteristics improves the model performance considerably. Specification 2 predicts the actually chosen alternatives with a substantially higher probability than Specification 1, particularly for frequent choices such as no employment, full-time employment in nursing (day shifts), full-time employment in nursing (irregular shifts) and full-time employment in other occupations.

Besides the model's performance in predicting variation in labour supply between individuals, one might also be interested in how well the model predicts variation in labour market behaviour within individuals over time. This is of particular interest since the model is estimated as a pooled cross-section. If individuals have an unobserved, time-constant preference for working in a certain employment type or for not working at all, and these unobserved differences are correlated with expected income in each of these alternatives, the estimated parameters of the utility function might reflect unobserved heterogeneity rather than the true utility from income and disutility from work. Although the model includes the family circumstances, this is only a small part of the differences between individuals and thus only contributes to some of the difference in individuals’ preferences. If the estimated utility function only reflects unobserved heterogeneity in time-constant preferences rather than the effect of income and hours of work on utility, it should not be possible to predict changes in an individual's labour market behaviour over time based on that utility function. However, if the estimated utility function predicts changes in the probability of the outcomes over time that match actually observed changes in choices over time, then the utility function contains at least some information on variation in behaviour over time within individuals.

To investigate the question, we correlate observed changes in choices over time $\left(Z_{i t}\right)$ with changes in the predicted probabilities for any given choice over time $\left(\Delta P_{j t}\right.$ and $\left.\Delta P_{k t}\right)$.

$Z_{i t}$ takes the value one if an individual experiences a transition from any alternative $k$ in period $t-1$ to any other alternative $j$ in period $t$, and zero otherwise: 


$$
Z_{i t}= \begin{cases}1 & Y_{i t}=j \wedge Y_{i t-1}=k ; k \neq j \\ 0 & Y_{i t}=j \wedge Y_{i t-1}=k ; k=j\end{cases}
$$

where $Y_{i t}$ denotes the labour supply choice of individual $i$ in period $t . j$ and $k$ are elements of the individual's choice set $M$ as described in Section 2. $k$ denotes the alternative that an individual chooses in $t-1$, and $j$ is the alternative that the individual chooses in $t . \Delta P_{j t}$ and $\Delta P_{k t}$ denote the change in the predicted probability of choosing either alternative $j$ or alternative $k$ :

$\Delta P_{j t}=\hat{P}\left(Y_{i t}=j\right)-\hat{P}\left(Y_{i t-1}=j\right)$, and $\Delta P_{k t}=\hat{P}\left(Y_{i t}=k\right)-\hat{P}\left(Y_{i t-1}=k\right)$.

We expect that $\rho_{j}=\operatorname{corr}\left(Z_{i t}, \Delta P_{j t}\right)>0$ and $\rho_{k}=\operatorname{corr}\left(Z_{i t}, \Delta P_{k t}\right)<0$. Note that we calculate the correlation of a transition from one alternative to another with the change in predicted probability of choosing the relevant alternatives, rather than with the change in the predicted utility of the alternative. This is because the individual chooses the alternative from choice set $M$ with the highest utility, and thus takes the change in utility in each alternative from choice set $M$ into account. The change in the predicted probability of choosing a given alternative thus also reflects changes in the estimated utilities from all other alternatives in the choice set $M$ relative to the utility in $j$ or $k$.

The sample contains 3276 observations in $t$, for which the individual's choice in $t-1$ is known as well. For 2030 observations, the individual's choices in $t$ and $t-1$ are the same. We observe 424 transitions within a given employment type to a higher or lower number of working hours, and 822 transitions into another employment type. Table B2 shows the resulting correlation coefficients. As expected, $\rho_{j}$ is positive and $\rho_{k}$ is negative for both specifications, and both are statistically highly significant at the $0.1 \%$-level, confirming that the model can indeed predict variation in behaviour within individuals over time, even though withinindividual variation over time has not been explicitly taken into account in the estimation.

Table B2: Correlation Between Within-Variation in Behaviour Predicted by the Model and Observed Within-Variation in Behaviour.

\begin{tabular}{|ll|ll|}
\hline & & $\rho_{j}$ & \multicolumn{1}{c|}{$\rho_{k}$} \\
\hline \multirow{2}{*}{ Specification (1) } & Corr Coeff. & 0.152 & -0.079 \\
& p-value & 0.000 & 0.000 \\
\hline \multirow{2}{*}{ Specification (2) } & Corr Coeff. & 0.120 & -0.057 \\
& -p-value & 0.000 & -0.000 \\
\hline
\end{tabular}




\section{Appendix C Robustness Checks - Variations in the Number of Labour Supply Points}

We have repeated the analysis with four, six and eight intervals of labour supply (resulting in 17, 25 and 33 discrete choices), to compare the estimated elasticities to the elasticities estimated in the specification with three points as in our baseline model. The unconditional elasticities of supplied hours in nursing with respect to net income, wages in nursing occupations, and wages in non-nursing occupations are presented in Table C1. Full results are available upon request from the authors.

Table C1: Unconditional Elasticity of Hours in Nursing Occupations

\begin{tabular}{|ll|cccc|}
\hline & & \multicolumn{3}{|c|}{ Number of labour supply points in specification: } \\
\cline { 1 - 2 } Elasticity w.r.t. & & $\begin{array}{c}\text { Model with 3 } \\
\text { points }\end{array}$ & $\begin{array}{c}\text { Model with } \\
\text { 4 points }\end{array}$ & $\begin{array}{c}\text { Model with } \\
\text { 6 points }\end{array}$ & $\begin{array}{c}\text { Model with } \\
8 \text { points }\end{array}$ \\
\cline { 1 - 2 } Increase in other net income by & Elasticity & -0.112 & -0.114 & -0.112 & -0.111 \\
$1 \%$ & Std. Err. & 0.038 & 0.037 & 0.039 & 0.034 \\
\cline { 1 - 2 } Increase in gross wage for & Elasticity & 1.374 & 1.356 & 1.365 & 1.348 \\
nursing occupations by 1\% & Std. Err. & 0.168 & 0.165 & 0.161 & 0.157 \\
\cline { 1 - 2 } Increase in gross wage for non- & Elasticity & -0.929 & -0.913 & -0.955 & -0.937 \\
nursing occupations by 1\% & Std. Err. & 0.126 & 0.123 & 0.127 & 0.123 \\
\hline
\end{tabular}

